NBER WORKING PAPER SERIES

\title{
CLIMBING OUT OF POVERTY, FALLING BACK IN: MEASURING THE PERSISTENCE OF POVERTY OVER MULTIPLE SPELLS
}

Ann Huff Stevens

Working Paper 5390

\author{
NATIONAL BUREAU OF ECONOMIC RESEARCH \\ 1050 Massachusetts Avenue \\ Cambridge, MA 02138 \\ December 1995
}

This work has benefitted from many helpful discussions with and comments from Gary Solon, Charles Brown, David Lam, Robert Moffitt, James Walker, and Marianne Page. Thanks also to Rebecca Blank for her encouragement to begin this work on poverty dynamics. Finally, valuable feedback was provided by participants in the University of Michigan Labor Seminar, and by seminar participants at several other universities. This paper is part of NBER's research program in Labor Studies. Any opinions expressed are those of the author and not those of the National Bureau of Economic Research.

() 1995 by Ann Huff Stevens. All rights reserved. Short sections of text, not to exceed two paragraphs, may be quoted without explicit permission provided that full credit, including $\odot$ notice, is given to the source. 


\title{
CLIMBING OUT OF POVERTY, \\ FALLING BACK IN: MEASURING \\ THE PERSISTENCE OF POVERTY \\ OVER MULTIPLE SPELLS
}

\begin{abstract}
This paper investigates the persistence of poverty over individuals' lifetimes using a hazard rate, or spells approach. Previous research on poverty dynamics using the spells approach has been limited by its failure to take into account multiple episodes of poverty. I estimate hazard models for exiting from and for returning to poverty and use the estimated parameters to calculate distributions of total time spent in poverty over multiple spells, using longitudinal data from the Panel Study of Income Dynamics. These models incorporate observable personal and household characteristics, as well as unobserved heterogeneity. My findings emphasize the importance of considering multiple spells in an analysis of poverty persistence. For black and white individuals falling into poverty in some year, approximately 50 and 30 percent, respectively, will have family income below the poverty line in at least five of the next ten years. A single spells approach predicts comparable figures of only 26 and 13 percent. To check the robustness of these predictions I also utilize two alternative approaches -- direct tabulations from panel data and estimation of a components-of-variance model -- and compare predictions of poverty persistence based on the three methods.
\end{abstract}

\section{Ann Huff Stevens}

Department of Public Policy and Center for Urban Policy Research Rutgers University 33 Livingston Avenue, Suite 202 New Brunswick, NJ 08901-1980 and NBER 
Questions regarding the persistence of poverty are central to much past and current debate on the extent of poverty and public policies to address it. Early discussions of a "culture of poverty" implicitly assumed that a sizable portion of the poverty population remained in poverty for many years. More recent discussions of the underclass and of long-term welfare dependency also presume that some individuals remain poor over much of their lifetimes. Issues of income dynamics in general have been frequently studied by economists, but there are additional reasons for focusing on dynamics at the bottom of the income distribution. Poverty, as measured by the ratio of household income to a minimum needs standard, is a state in which individuals' current resources are insufficient to meet basic needs. If poverty persists for many years, policy-makers and others have good reasons for concern over the consequences of such long-term deprivation. Recent proposals to limit the duration of welfare receipt point to another reason for studying the persistence of poverty. Because government programs frequently provide assistance to those in poverty, it is important to document the extent to which certain individuals remain in poverty, and so remain eligible for public assistance, year after year. While interest in income and poverty dynamics has a long history, one very basic question has not been answered: how long will an individual falling into poverty spend below the poverty line? This question is central to our understanding of the concentration of poverty and of the degree of mobility in the lower portion of the income distribution.

This paper contributes to the literature on poverty dynamics in two ways. First, it provides estimates of the time spent in poverty over a relatively long time frame and over multiple spells of poverty. This fundamental measure of the persistence of poverty has not been estimated in previous work. I estimate poverty persistence using two sets of hazard rates for 
movements into and out of poverty, controlling for observable characteristics and for unobserved heterogeneity in exit rates. This technique produces estimated distributions of time spent in poverty for individuals just beginning a poverty spell, with a variety of individual and household characteristics. Second, I supplement these estimates with results based on another approach in the poverty dynamics literature involving the estimation of components-of-variance models. I then compare the results from these two models to each other and to those from a simpler method of directly tabulating years poor from panel data. These different models of poverty dynamics have rarely been estimated together, and the two approaches used here have not been compared in terms of their predictions of time spent in poverty.

\section{Previous research on poverty persistence}

Previous authors have used several different approaches to study the dynamics and persistence of poverty. ${ }^{1}$ Initial research into this area made use of newly available longitudinal data to observe and count the number of years individuals spend poor out of a fixed sample period. ${ }^{2}$ The primary shortcoming of this strategy is that people who end (or begin) the period in poverty may be starting (or ending) a long stay in poverty, despite the fact that they appear to be poor in only one or two of the observed years. This leads to an understatement of persistent poverty, since some of those observed to be poor only a short time are actually in the midst of lengthy poverty spells that are censored by the beginning or end of the sample frame. In

\footnotetext{
1 These methods have previously been summarized by Bane and Ellwood (1986) and Duncan and Rodgers (1991) among others.

2 Duncan et al. (1984), for example, used PSID data on individuals from 1969 through 1978 to count the number of years in which household income fell below the poverty line. They found that 33 percent of the sample experienced poverty in at least one year, but only about five percent were "persistently" poor, defined as being in poverty for eight out of the ten years.
} 
addition, these methods do not lend themselves to multivariate analyses of factors affecting the persistence of poverty.

Another commonly used method in the literature on income and poverty dynamics involves the estimation of components-of-variance models to describe the evolution of earnings or income over time. Lillard and Willis (1978) first applied this method to study poverty in their examination of earnings mobility in a sample of male household heads. Using their estimates of the permanent and transitory variance components of male earnings, Lillard and Willis derived probabilities of various time sequences of poverty or low-earnings status. Because their study was limited to the earnings of male heads of households, the authors noted that a more complete analysis of poverty within their framework would require incorporating family income (rather than male earnings) and changes in family composition over time, along with other factors.

Since the Lillard and Willis study, many authors have used variations of the permanenttransitory approach to study questions relating to poverty. ${ }^{3}$ Only rarely, however, have these methods been applied to measures of family income or the family income-to-needs ratio used in conventional definitions of poverty in the United States. ${ }^{4}$ In addition, many applications have continued to focus on male heads of household, or two-parent households, and thus missed much of the long-term poor population. Finally, while the parameters of these models can be used to derive probabilities of spending any number of years in poverty, this has not been done in most

3 Gottschalk (1982), for example, estimates the percentage of married males with permanently low earnings using similar techniques.

4 One example is Duncan and Rodgers (1991) who apply components-of-variance techniques to the income-toneeds ratios for samples of black and white children. Similarly Duncan (1983) estimates permanent-transitory models for six year samples of men, women, and children. Neither of these studies use the estimated parameters to derive distributions of time spent in poverty. 
applications. The estimated variance components are often used to distinguish "permanent" from "transitory" poverty, rather than estimating distributions of time spent below the poverty line.

A different approach to the measurement of poverty persistence was used by Bane and Ellwood (1986). These authors used a spell-based, or hazard rate approach in their work. They focused on individual spells of poverty--consecutive years in which total household money income was less than the poverty line--and estimated the probability of ending these poverty spells, allowing for duration dependence in the hazard rate. This study offered several advantages over some previous research. First, right-censored spells, those in progress at the end of the sample period, are easily incorporated into hazard rate models. Persons who remain in poverty through the end of the sample contribute to the estimation of exit probabilities (through the denominator of the exit rate) in all years through the censored year. Second, the spells approach easily incorporates poverty transitions involving discrete changes in household structure, and provides a way to highlight the events associated with transitions into and out of poverty. Third, while Bane and Ellwood did not explore temporal changes in poverty exit rates, their approach is well-suited to examination of the effects of time-varying factors on poverty persistence. Finally, Bane and Ellwood derived a variety of distributions based on the estimated exit rates, and clarified differences between the length of time in poverty for a person currently poor, and for someone just entering poverty. The findings of this study emphasized that, while most of those who fall into poverty will experience relatively short spells, the bulk of those currently poor are in the midst of a lengthy stay in poverty. 
Despite these advantages, a major drawback of the Bane and Ellwood study is its focus on single spells. ${ }^{5}$ Particularly in the years just after an exit from poverty, individuals are likely to fall back below the poverty line. I find that half of all individuals ending a poverty spell in a given year will again have incomes below the poverty line within four years. This results in a very different distribution of total years spent below the poverty line, as I show below. 6

In this paper I begin by developing a hazard model to account for multiple spells of poverty, and use this model to derive estimates of total time poor. While either the spells framework or a components-of-variance model could serve as a starting point for this examination of poverty dynamics, I begin with the spells approach for several reasons. For consistency with "official" definitions of poverty, and to account for important differences in welfare across households of different sizes with the same total income, I use the income-toneeds ratio, or total household income relative to a size-adjusted minimum needs standard. While components-of-variance models have been widely used and tested for earned income, ${ }^{7}$ it is less clear which, if any, existing models are applicable to the income-to-needs ratio. Human capital theory provides some guidance in developing models for earned income; these theories are less directly applicable to the dynamics of household income-to-needs. Additionally, the spells approach easily allows for estimation over a variety of age groups and household

\footnotetext{
5 Bane and Ellwood did adjust their calculations to take into account some of the multiple spells that result from very brief periods above or below the poverty line. This still left many individuals in their sample experiencing more than one spell in the observed time frame, however. They reported that 31 percent of individuals in their sample experienced a second spell of poverty. This underestimates the true number of repeated spells since it does not account for right-censoring at the end of the sample; individuals exiting poverty spells near the end of the sample period will not be observed re-entering poverty before the end of the sample.

6 The importance of multiple spells has been noted in the literature on spells of welfare receipt. See, for example, Gottschalk and Moffitt (1994), or Ellwood (1986). The same point has not previously been made with respect to poverty spells.

7 Even with respect to earned income among adult males, there is controversy over which models best capture the dynamics. See Baker (1995).
} 
structures, and for changes in household structure over time. Variance components models have typically been estimated on relatively homogeneous groups, and on households with unchanging composition. For these reasons I begin by extending the hazard rate approach to consider poverty persistence over multiple spells. Given the frequency with which variance components models appear in the earnings dynamics literature, however, I supplement the hazard model analysis with predictions of poverty persistence based on a variance components model of household income-to-needs.

\section{Estimation strategy}

\section{a. Basic hazard rate model}

My strategy in this paper centers around the estimation of two hazard rates: one for leaving poverty, and one for returning to poverty. In theory, I could also estimate rates of first entry (as opposed to re-entry) into poverty, but have chosen not to include first entry rates in this study. Including these rates would require that I observe individuals from birth forward to identify their initial entry into poverty. This means that I could, at most, directly estimate firstentry rates only up to age 22 (the length of the panel). Further, these estimates would be based on very small samples of individuals born into the survey since 1967. I thus restrict the scope of this paper to the estimation of exit and re-entry rates, and focus on the persistence of poverty for those who ever become poor.

For now, assume that I start with a sample of spells with known durations. Let the probability of exiting poverty in any given year be represented by a standard logit specification. The probability of ending a spell of poverty after $d$ years is given by the hazard function 


$$
\lambda_{i d t}^{p}=\frac{\exp \left(y_{i d t}\right)}{1+\exp \left(y_{i d t}\right)}
$$

$$
y_{i d t}=\alpha_{d}^{p}+\beta^{p} X_{i t}
$$

The subscript $i$ indexes individuals; $t$ refers to calendar years, and $d$ indexes duration of the current spell. Equation (2) shows that the exit probabilities are functions of duration effects $\left(\alpha_{d}\right)$ and of other variables in $\mathrm{X}$ that may vary across people and across time, including calendar year dummies. The superscript $p$ distinguishes the hazard rate for ending a poverty spell from the hazard for ending a non-poverty spell, shown below. The probability of observing a completed poverty spell of length $d$ is

$$
f(d)=\left[\prod_{s=1}^{d-1} \frac{1}{1+\exp \left(y_{i s t}\right)}\right]\left[\frac{\exp \left(y_{i d t}\right)}{1+\exp \left(y_{i d t}\right)}\right]
$$

The first term in (3) represents the probability of not exiting in each of the years prior to the dth year, and the second term is the probability of ending the spell in year d. Some of the spells in the data will continue beyond the end of the sample period, and these are easily incorporated into this framework. The probability of observing a right-censored spell is

$$
1-F(d)=\prod_{s=1}^{d} \frac{1}{1+\exp \left(y_{i s t}\right)}
$$

Once an individual has ended a poverty spell, the probability of returning to poverty over the next several years can be modeled in the same way. The hazard function for returning to poverty is

$$
\lambda_{i d t}^{n}=\frac{\exp \left(z_{i d t}\right)}{1+\exp \left(z_{i d t}\right)}
$$




$$
z_{i d t}=\alpha_{d}^{n}+\beta^{n} X_{i t}
$$

The $d$ subscript now refers to the duration of the spell out of poverty. The probability of a spell out of poverty lasting for $d$ years is

$$
g(d)=\left[\prod_{s=1}^{d-1} \frac{1}{1+\exp \left(z_{i s t}\right)}\right]\left[\frac{\exp \left(z_{i d t}\right)}{1+\exp \left(z_{i d t}\right)}\right]
$$

The contribution of a right-censored spell to the likelihood function is

$$
1-G(d)=\prod_{s=1}^{d} \frac{1}{1+\exp \left(z_{i s t}\right)}
$$

These specifications are initially used to estimate, separately, exit rates from poverty and re-entry rates into poverty.

\section{b. Unobserved heterogeneity}

The model above assumes that, controlling for duration and various observable characteristics, individuals' exit probabilities are independent across years. This will not be true, however, in the presence of unobservable person-specific characteristics that affect mobility out of and back into poverty. Further, once I allow for multiple spells, it may be particularly important to control for unobservable characteristics that influence individuals' transition rates. Allowing for correlation across an individual's exit and re-entry probabilities over time may be necessary to accurately estimate total years spent in poverty over a relatively extended time period. A person who has previously experienced a long poverty spell and then re-enters poverty, for example, may be more likely to experience a long second spell. It may also be the case that re-entry rates are related to exit rates from poverty; persons with particularly high exit rates from poverty may also have lower re-entry rates. To better capture the correlation across 
individual spells, the entry and exit rates can be modeled together in one likelihood function, with terms added to control for unobserved heterogeneity.

A framework in which a component of the hazard function persists across multiple spells for the same individual has been used in the unemployment spells literature by Ham and Rea (1987), using the methodology suggested in Heckman and Singer (1984b). Using a similar approach, I can specify a likelihood function that links spells of poverty, and the intervening spells out of poverty, experienced by an individual. The additional complication to be addressed here is that heterogeneity components must enter two types of spells--those in and out of poverty--and the correlation across the two types of spells must be estimated. 8

I allow heterogeneity to enter the hazard function through intercept terms in $y$ and $z$ above. Equations (2) and (6) above are modified to include an individual specific effect:

$$
\begin{aligned}
& y_{i d t}=\theta_{i}^{p}+\alpha_{d}^{p}+\beta^{p} X_{i t} \\
& z_{i d t}=\theta_{i}^{n}+\alpha_{d}^{n}+\beta^{n} X_{i t}
\end{aligned}
$$

I assume that $\theta^{p}$ and $\theta^{n}$ can be characterized by discrete distributions with two support points each. There are two types of people with respect to spells of poverty. Type $1 \mathrm{~s}$ with respect to poverty spells occur in the population with some probability and have an intercept term given by $\theta_{1}^{p}$; similarly, type $2 s$ have an intercept term $\theta_{2}^{p}$. I also allow for two types of people with respect to spells out of poverty. Some proportion of the population have an intercept term in equation (6a) above of $\theta_{1}^{n}$; the remaining proportion of the population have an intercept of $\theta_{2}^{n}$.

\footnotetext{
8 Eberwein, Ham, and LaLonde (1994) use a similar model for spells in and out of employment.
} 
Given this structure for the heterogeneity across spells in and out of poverty, the population of individuals ever becoming poor is characterized by the joint distribution of $\theta^{p}$ and $\theta^{n}$. Individuals differ in two unobserved ways--their tendency to escape poverty, and their tendency to return to poverty. The joint distribution describing this heterogeneity is summarized in the two-by-two table below. $R_{1}$ through $R_{4}$ are the probabilities of observing each of the four types of individuals, with $R_{1}+R_{2}+R_{3}+R_{4}=1$.

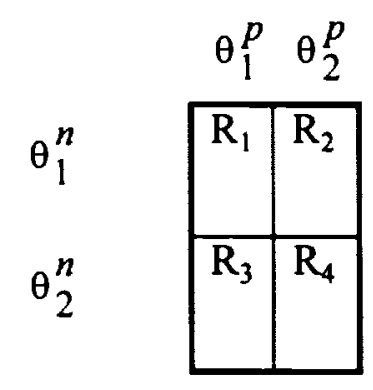

Each person is characterized by the vector

$$
\underline{\theta}_{i}=\left(\begin{array}{c}
\theta_{i}^{p} \\
\theta_{i}^{n}
\end{array}\right)
$$

Now, the contribution to the likelihood function conditional on a person's 'type', $\underline{\theta}_{i}$, can be written as

$$
L_{i}\left(\underline{\theta}_{i}\right)=\prod_{s=1}^{n 1 i} f_{i s}\left(d ; \underline{\theta}_{i}\right) \prod_{s=1}^{m 1 i} g_{i s}\left(d ; \underline{\theta}_{i}\right) \prod_{s=1}^{n 2 i}\left(1-F_{i s}\left(d ; \underline{\theta}_{i}\right)\right) \prod_{s=1}^{m 2 i}\left(1-G_{i s}\left(d ; \underline{\theta}_{i}\right)\right)
$$

The term nli represents the number of non-right censored spells of poverty an individual contributes to the function; $\mathrm{mli}$ is the number of non-right censored spells out of poverty. Right- 
censored spells of poverty and non-poverty are indexed by $n 2 \mathrm{i}$ and $\mathrm{m} 2 \mathrm{i}$. Summing over these conditional probabilities, each individual contributes to the likelihood function

(11) $L_{i}=\sum_{k=1}^{4} R_{k} L_{i}\left(\underline{\theta}_{k}\right)$

The likelihood function described by (10) and (11) can now be maximized with respect to $\alpha_{d}, \beta, R_{k}$ and $\underline{\theta}_{k}$.

The restriction that the joint distribution of the heterogeneity terms is characterized by just four support points may seem severe. An alternative would be to specify a specific distribution for the heterogeneity with respect to each type of spell. However, because I must also link the two types of spells (poverty and non-poverty), this would require specification of a particular bivariate distribution as well. I prefer to let the relationship between poverty and nonpoverty spells be characterized in this more tractable manner. As I show below, this model captures the actual distribution of years in poverty well.

\section{c. Left-censored spells}

To this point I have not discussed incorporating spells that begin prior to the start date of the sample, in 1967. If the true model were in fact driven only by spell duration, with no role for unobserved heterogeneity, this approach would give consistent estimates of poverty transition rates for the population (Heckman and Singer, 1984). This is not the case, however, if unobserved heterogeneity is a factor in the hazard rates. By eliminating those spells in progress at the start of the sample in the presence of this heterogeneity, I induce a form of selection bias. Specifically, individuals who begin new spells after 1967 are likely to have higher transition probabilities (since they have experienced at least one transition since 1967) than the overall 
population. Some of those poor in 1967 will eventually be included in the analysis, of course. If an individual who is poor in 1967 exits an initial spell, he or she will then be included in the estimation of the re-entry hazard. Some of these people will be observed to begin a new spell of poverty, and so be included in the estimation of exit rates. Those who are poor in 1967 and remain poor for many years, however, are selected out of the sample entirely. This may result in over-estimation of exit rates from poverty at long durations if the left-censored spells are not incorporated.

One way to evaluate the severity of this bias from dropping left-censored spells may also provide a straightforward way to incorporate these spells. Duration dependence in the hazard rate is likely to diminish with duration. Suppose I specify the duration terms with separate effects for durations of up to five years, and one more effect for spells of six years or longer. Using this specification, I can now estimate the model using data from 1973 through 1988 . In 1973, I observe whether each person has been poor in the previous six years (since 1967), and so can use all poverty spells currently in progress in the estimation, including those that began prior to the start of the sample and now have durations of six years or more.

This approach will show the extent to which exit rates from longer spells are biased when the estimation is based only on non-left-censored spells. It is costly in terms of the information on temporal changes in exit rates, since it requires me to eliminate four years of data. If the necessary restrictions on the duration terms are plausible, however, this provides a simple way to incorporate left-censored spells. Further, while this approach reduces the number of years available for the estimation, it increases the cross-sectional size of the sample in each year. 
More formal techniques also exist for dealing with left-censored spells. In particular, Heckman (1981) describes the inclusion of left-censored spells in the likelihood function. The left censored spells are included by integrating over all possible "histories" up to the point of censoring. This is the method implemented in Moffitt and Rendall (1993), in a study of spells of female headship. Several considerations lead me not to pursue this strategy here. First, it is unlikely that a model including both the left-censored spells (and integrating over all possible histories), along with the unobserved heterogeneity, would be computationally tractable. A related point is that one reason the model used by Moffitt and Rendall is tractable, is that they condition the hazard rates only on age and calendar year (along with duration), both of which can be completely "backcast" and so contribute the necessary pre-sample information to the likelihood function. Most of the models I estimate include, in addition to unobserved heterogeneity, variables such as sex and education of the household head that change over time and that would be more difficult to specify for the left-censored spells. Finally, and most importantly, the evidence I present below suggests remarkably little bias stemming from the treatment of left-censored spells. Given this, I rely on some simple testing and modification of the duration specification to include the left-censored spells.

\section{d. Interpretation of transition probabilities}

Given estimates of transition rates out of and back into poverty, it is important to be able to interpret these hazard rates in terms of time spent poor. In their work on single spells of poverty, Bane and Ellwood (1986) calculated the distribution of single spell lengths implied by their exit rates for persons beginning spells of poverty. A similar strategy can be followed here to estimate the total number of years out of the next $S$ years that will be spent in poverty. The 
distributions estimated by Bane and Ellwood (1986) provide estimates of the length of time spent in poverty if only one spell of poverty is experienced. Suppose, instead, that individuals can experience two spells of poverty. Then, the distribution of years spent poor by a person falling into poverty can be calculated as 9

$$
\begin{aligned}
& {\left[\sum_{d 1=1}^{d-1} \sum_{d 2=1}^{S-d} f(d 1) g(d 2) f(d-d 1)(1-G(S-d-d 2))\right]} \\
& +\left[\sum_{d 1=1}^{d-1} \sum_{d 2=1}^{S-d-1} f(d 1) g(d 2) f(d-d 1) g(S-d-d 2)\right] \\
& +\left[\sum_{d 1=1}^{d-1} f(d 1) g(S-d)(1-F(d-d 1)]\right.
\end{aligned}
$$

The functions $f, g, F$, and $G$, are defined in equations 1-7 above. The first two terms in brackets represent the probability of spending $d$ years in poverty ( $d 1$ of these in the first spell, the remainder in a second spell) and ending the period of S years out of poverty. The second term gives the probability of spending $\mathrm{d} l$ years poor, S-d years not poor and ending the period in poverty. Expressions for years spent poor over three or more spells can be similarly derived, and then combined to give the complete distribution of years spent poor in multiple spells of poverty out of the next $S$ years.

A limitation of this method of interpreting the exit and re-entry rates is that it requires that one set of transition rates be applied over the course of a person's lifetime. It does not take into account that exit and re-entry rates may vary with age. An alternative way to summarize the relationship between the estimated transition rates and time spent poor is presented in Moffitt and Rendall (1993) and in Gottschalk and Moffitt (1994). In these studies of transition rates into

\footnotetext{
9 This is similar to an expression derived in Coleman (1989) for multiple spells of unemployment.
} 
and out of female headship and welfare participation, the authors use microsimulation techniques to estimate the lifetime distributions of time spent as female heads and on welfare. The same techniques can be applied here to incorporate age and other time-varying effects into the predicted poverty sequences. This method is described more fully in section IV.

\section{Data and samples}

The data for this study come from the 1968 through 1989 interview years of the Panel Study of Income Dynamics, and correspond to calendar years 1967 through 1988.10 The PSID collects data on household and individual earnings, income, family composition and labor market status, among other characteristics. All persons are included in the analysis in each year they are present in the sample, including those who leave prior to the end of the survey. 11 Sample sizes are shown in Table A1. Since I use only years 1973 through 1988 in the analysis including leftcensored spells, sample sizes for these years are shown as well. The unit of analysis in the hazard rate estimation is the individual, although the poverty definition relies on each individual's household income-to-needs level. This is necessary to allow for individuals to move from one household situation to another over time.

The definition of poverty follows the official Census Bureau poverty line. Individuals are considered poor in any year that their total household money income is less than the appropriate needs standard for their household size. The needs standard for the poverty cutoff is defined as

10 For most of the results presented, only data for calendar years 1969 forward are included in the estimation. Data for the first two years of the sample are not used since, initially, only spells starting after the beginning of the sample are included. Left-censored spells are later incorporated, using only the data from 1973 forward. 11 One group not included in the sample is individuals joining the survey after 1967 through marriage or other movements into existing survey households. These individuals are considered "non-sample" persons by the PSID. Since the PSID sample and weights are designed to be representative without including these non-sample persons, I do not include them in the analysis. In contrast, people who are born to original PSID sample members are included. 
1.25 times that used in the Census Bureau poverty guidelines. This definition is commonly used by researchers working with PSID data and is meant to account for the consistently higher reported income in the PSID than in Census Bureau data.

Finally, as is well known, the PSID is not a random sample; the original survey oversampled low-income households. This selection based on poverty status means that all estimates must be weighted to consistently estimate population parameters. All of the hazard model results reported below are weighted using the PSID sample weights. This weighting, and the clustered sample design of the PSID, mean that traditional standard error estimates will be biased. To correct for this bias, standard errors are estimated using the method of balanced repeated replications (see Kish and Frankel, 1970); these methods are discussed in more detail in the Appendix. Another source of bias in traditional standard error estimates is that I use multiple individuals from the same household and so observations within households are not independent. The techniques to address problems associated with the clustering induced by the survey design will also correct for this lack of independence within families.

\section{Results from the hazard rate model}

\section{a. Without unobserved heterogeneity}

To establish the broad patterns of exit from and re-entry into poverty, I first present simple non-parametric estimates of the exit and re-entry rates by race. 12 Table 1 shows hazard rates calculated by dividing the number of individuals ending a spell after exactly $\mathrm{d}$ years poor by the total number poor (or non-poor for the re-entry hazard) for at least $d$ years. As expected, both

12 The results presented here are for "whites" and "blacks." The black category includes very small numbers of other races as well. The results are not sensitive to dropping these individuals from the sample, or, alternatively, including them in the whites category. Sample sizes are too small for a separate analysis of this group. 
exit and re-entry rates decline substantially with duration. The probability of ending a poverty spell after one year poor is .53 ; after four years in poverty the exit rate is .23 . The re-entry rates show the substantial risk of returning to poverty and the importance of multiple spells. Among blacks, the probability of returning to poverty after one year out is more than a third. Even through the sixth year out of poverty, blacks have re-entry rates in excess of .10. Differences by race show the greater persistence of poverty among blacks, as the consequence of both lower exit rates and higher re-entry rates. Standard error estimates in Table 1 (and in Tables 2 through 5) are calculated using balanced half-sample techniques, and are more fully described in the Appendix. 13

A more useful way to view the transition rate estimates is in terms of their implications for the number of years spent poor. The estimated transition rates from Table 1 are used to calculate the number of years spent poor over the next ten years, for persons just starting a spell of poverty, using formulas such as the one given by equation (12). The first column of Table 2 shows the distribution of years spent poor in single spells of poverty, calculated using only the exit rates, and not taking multiple spells into account. Column two uses both the exit and reentry rates to estimate years spent poor over multiple spells. These numbers are the probabilities that a person just falling into poverty will be poor for a given number of years out of the next ten. The final column of Table 2 comes from observing cohorts of persons entering poverty during each of the years from 1968 through 1979, and counting years poor over the next ten years. This

\footnotetext{
13 This method makes a substantial difference in the estimation of the standard errors. The standard errors resulting from this method are typically two to two and a half times as large as those calculated without correcting for the non-independence of observations. This ratio is larger than that typically reported by individuals correcting for "design effects" using the PSID data (see Hill, 1981, for example). That is because use of multiple family members from the same household causes an additional source of "clustering" and an additional source of bias in conventional standard error estimates.
} 
is a slight modification of the technique of directly tabulating observed years in poverty discussed in section l, conditioning on entry into poverty to avoid problems with censoring of spells in progress. These direct tabulations provide a useful benchmark for evaluating the accuracy of the hazard model.

The distributions in columns one and two of Table 2 illustrate the difference between single and multiple spell measures of the persistence of poverty. The distribution of single spell lengths suggests that a considerably larger proportion of the population will experience short stays in poverty than do the other columns. Comparing columns two and three shows the extent to which the simple hazard models capture the observed distribution of years poor following entry. The simulated distributions of years poor over multiple spells differ somewhat from those based on directly tabulating years poor. In particular, the simulated distributions consistently underestimate the proportion of individuals who will be poor for very few years. This is not surprising, given the relatively simple manner in which multiple spells have been combined. By controlling for important observable characteristics, as well as for unobserved heterogeneity, in the remainder of this section, the hazard model can better capture observed patterns. Despite this divergence, however, the picture of total time spent poor based on the multiple spell exit and reentry rates is a much better predictor of observed poverty persistence than are the single spells. The means of the distributions in columns two and three are 4.4 and 4.0 years, compared to a mean duration of single spells of just 2.7 years.

To introduce additional covariates into the hazard functions, I next estimate the exit and re-entry rates using the logit framework described above. Tables 3 and 4 contain the estimated coefficients from the logit estimation. These estimates are based on models that include controls 
for calendar year, age, education of the household head, and sex of the household head, in addition to the duration terms. 14 In PSID terminology the male is the default "head of household" and so a female head in this context is equivalent to a single female head of household. I initially allow separate duration effects for durations of one to nine years, and another for durations of ten years or more. The predicted hazard rates based on these logit estimates can be derived by substituting the estimated coefficients into the hazard functions given in equations (1) and (5).

The results in Tables 3 and 4 show that characteristics of individuals and their families impact the probabilities of exiting and returning to poverty in predictable ways. The education level of the household head and whether the household is headed by a single female have relatively large impacts on the exit and re-entry rates. The effect on exit rates of being in a female-headed household is summarized by a logit coefficient of -.77 for the overall sample. This translates into hazard rates for leaving poverty after one year of .39 for those in femaleheaded households, compared with .58 for those in households with male heads. The impact of female headship on re-entry probabilities is large as well. After one year out of poverty, those in households headed by women have a re-entry probability of one-third; the comparable figure for those in male-headed households I just under one-fifth. The impact of female headship and educational levels will be more full illustrated below when microsimulation techniques are used to derive distributions of time spent poor by individuals with different characteristics.

These tables also illustrate the age patterns of poverty transitions. Exit rates from poverty are lowest for young children and peak at ages 18 through 24 , reflecting the fact that many

\footnotetext{
14 Models were also estimated with a variety of interaction terms, as well as a few additional characteristics; estimated coefficients for these terms were generally not significant.
} 
poverty transitions involve household structure changes that are relatively common during early adulthood. Exit rates fall somewhat for individuals aged 55 and over. Re-entry rates follow the reverse pattern, reaching a minimum for adults ages 25 to 34 .

Variation in the hazard rates by year are also reflected in Tables 3 and 4 . The year-toyear differences in the hazard rates partially reflect changes in overall economic conditions. During the recession of 1975 , for example, the exit rate falls from .62 to .51 and the re-entry rate is somewhat higher than average. These variations across years are due to both business cycle influences and longer term trends. Over time, there has been a slight downward trend in exit rates, controlling for aggregate business cycle conditions. For example, the rate of GNP growth was 2.5 percent in 1979 and a slightly higher 2.7 percent in 1986; the exit rates from poverty (at a duration of 1 year) in these years, however, were .64 and .58 .15 The re-entry rates over time show less of a trend, and also have a somewhat weaker relationship to the state of the aggregate economy.

I have also investigated the importance of the events associated with beginning and ending poverty spells in predicting the length of a spell in or out of poverty. In their work on poverty spells, Bane and Ellwood identified events associated with the beginnings and endings of spells and examined implications of the type of beginning event on the length of poverty spells. Following Bane and Ellwood, I define events associated with starting and ending spells of poverty. First priority is given to household composition changes, such as marriage, divorce or separation, children leaving the parents' home, and other changes affecting the head of household. For those in households not undergoing such changes within a year of the beginning

15 These year effects can be more formally decomposed by regressing the estimated year effects on a trend term and a business cycle indicator. These results are discussed in Stevens $(1994,1995)$. 
or ending of the poverty spell, a determination is made as to whether the income or the needs component (in real terms) of the income to needs ratio changed by more. If income is the major factor in moving a household above or below the poverty line, the major source of that income change is identified.

I find relatively few significant effects of these event types on the transition probabilities. One exception is that black children born into poverty face significantly lower exit probabilities than those beginning poverty spells in other ways. This effect is very small and not statistically different from zero for whites, however. In the re-entry hazard, I find that those recently ending poverty spells primarily through an increase in unearned income are more likely to return to poverty, although this effect is also statistically significant only for blacks. One difference between these results and the differences in spell length by beginning events reported in Bane and Ellwood (1986) is that I control for several personal and household characteristics in addition to incorporating the event indicators. In particular, inclusion of age and female headship controls reduces the estimated effects of many of the beginning and ending event variables. Overall, the length of spells in or out of poverty does not vary substantially by the nature of the associated transitions across the poverty line. In particular, conditional on the variables shown in Tables 3 and 4, transitions out of poverty related to household structure changes are not systematically more or less permanent than those involving changes in income with a static household composition. 16

In the models estimated thus far, duration effects have been limited to the effects of current spell duration on current exit probabilities. As noted earlier, however, is it also likely

\footnotetext{
16 The control for female headship, of course, is a proxy for one of the major household structure changes and this has very large impacts on poverty persistence, as is illustrated below.
} 
that there are important correlations across individual spells in and out of poverty. Those experiencing one long poverty spell may have both higher re-entry probabilities, and lower exit rates in future spells. A direct method for testing this hypothesis is to include lagged duration terms in the hazard rates. For the re-entry hazard, a term was added for the length of the previous poverty spell. The results confirm that those experiencing relatively long stays in poverty are more likely to return to poverty. There are differences in the probability of remaining out of poverty by the length of the previous poverty spell. Among blacks, for example, approximately half of all individuals ending a short poverty spell remain out of poverty for at least five years. For those experiencing longer spells, only 37 percent stay above the poverty line for at least five years.

The length of the previous poverty spell was also entered into the hazard for exiting poverty, for the subsample experiencing at least two spells of poverty during the sample period. These results also provide evidence of correlations across poverty spells for the same individual. The expected poverty spell length for individuals with a previous spell of less than five years is 2.3 years for whites and 3.9 years for blacks. For those with a previous spell of five years or longer, the expected duration of poverty spells for whites and blacks are 4.8 and 5.6 years. Individuals who have recently experienced long spells in poverty are at higher risk for more subsequent poverty, through both higher re-entry probabilities and lower than average exit probabilities in the future. These correlations across spells in transition probabilities are modeled below through the introduction of unobserved heterogeneity terms that are correlated across spells. 


\section{b. Left-censoring}

Before examining the effect of unobserved heterogeneity on the hazard rates, one additional issue must be addressed. In Section II I noted the potential biases that arise if leftcensored spells are not included in the hazard rate estimation. To examine the extent of this bias, I slightly modified the duration specification so that the left-censored spells could be incorporated. First, I reduced the number of duration variables in the hazard rates from ten to six. Given the estimates of the duration terms reported in Tables 3 and 4 , this is a reasonable restriction. Beyond six years, the hazard functions estimated separately for blacks and whites begin to fluctuate and the duration terms no longer decline monotonically. Additionally, the size of the standard errors suggests that the duration terms beyond six years are not significantly different from one another. A Wald test confirms that for both blacks and whites the hypotheses of equality of the duration terms beyond six years cannot be rejected.

Inclusion of the left-censored spells makes remarkably little difference to the estimated transition probabilities. The predicted exit rates for durations of six years or longer are .15 and .16 with and without the left-censored spells, with standard errors of approximately .01 . Estimated re-entry rates with and without the left-censored spells of six years or more are .03 and .02. Overall, the bias from omitting left-censored spells appears to be extremely small. ${ }^{17}$ For the remainder of the paper I include the left-censored spells of poverty in the analysis and specify the duration terms in this way. This will eliminate potential bias in the estimation of the heterogeneity parameters discussed in the next section.

17 An alternative examination of the importance of left-censoring was also performed. I used all non-left-censored observations to estimate the model with ten duration terms allowed, along with age and calendar year variables. I then artificially left-censored this sample at 1973 and eliminated those spells that were in progress in 1973 . The comparison of samples left-censored in 1968 and in 1973 showed virtually no effect of the additional left-censoring. 


\section{c. Incorporating unobserved heterogeneity}

I next estimate the hazard rates allowing unobserved heterogeneity to influence the hazard over individuals' lifetimes. The likelihood function given in equations (9)-(11) is maximized with respect to the parameters of the hazard functions and the parameters of the discrete distribution of the heterogeneity terms. I first estimated hazard rates from poverty and non-poverty spells separately, allowing for a two point heterogeneity distribution in both types of spells. The results from this estimation were used to obtain starting values for the estimation of the function involving both speils in and out of poverty. Table 5 shows these estimated parameters. Because I have included a full set of duration dummy variables, one of the support points of the heterogeneity distribution is normalized to zero. This model was estimated without calendar year effects and those results are shown in Table 5. Inclusion of year effects does not alter the estimated heterogeneity or other parameters.

Initially, as described in Section II, I allowed the heterogeneity terms with respect to exit and re-entry to be freely correlated with one another, so that there were four possible types in the population. In the case of whites, the estimation indicated that the probabilities corresponding to two of the cells in the table were very close to zero. I thus restricted the heterogeneity terms to allow for only two types of individuals in the case of whites. 18 Ninety-six percent of the population are found to face relatively high rates of exit from poverty and relatively low rates of re-entry. Exit rates for the reference group (adults in households headed by males with less than a high school education) are .64 in the first year of a poverty spell and decline to around .28 after

\footnotetext{
18 The probabilities are actually entered into the likelihood function as a cumulative normal function, in order to restrict the estimates to be between zero and one. For two cells in the table the arguments in the cumulative normal function were estimated at around -200, implying probabilities very close to zero. Restricting these probabilities to be equal to zero did not affect other estimated support points, probabilities, or coefficients.
} 
six or more years in poverty. Re-entry probabilities for this group range from .17 in the initial year out of poverty to .04 after six or more years out.

The balance of the white population, four percent, face very low probabilities of escaping poverty, ranging from .25 to .07 for the reference group. The probability of returning to poverty among individuals of this "type" is very high, starting at .86 in the initial year following a poverty spell, and declining only to .55 after six or more years.

The results for blacks shown in Table 5 show a somewhat different pattern. Forty-four percent of blacks are estimated to have relatively high exit rates and low re-entry rates. For this group of blacks, exit rates range from .63 after 1 year in poverty to .28 after six or more years; reentry rates range from .24 to .06 . These rates are very close to the estimated transition rates for the bulk of the white population noted above. At the other extreme, fourteen percent are estimated to have low rates of exit and high rates of re-entry. Relative to whites, and in keeping with previous research on persistent poverty, a substantially larger proportion of the black population falling below the poverty line (fourteen versus four percent) will face extremely persistent poverty. Another difference in poverty dynamics for blacks is that a third category makes up a substantial part of the overall population. Forty-two percent of blacks are estimated to have relatively low exit rates, but also low rates of re-entry. This group experiences long spells of poverty, but does not face the extremely high re-entry probabilities that are consistent with permanent poverty.

The standard errors on the estimated heterogeneity parameters for blacks are large, and indicate that these parameters are estimated imprecisely. Further, some caution is necessary with respect to the estimated standard errors in the columns for blacks in Table 5. The repeated half- 
sample technique used to generate standard errors involves performing the maximum likelihood estimation 32 times on different half-samples. For blacks, in nine of the 32 half-samples the model did not converge from a variety of starting values and so maximum likelihood estimates were not available. The standard errors shown in Table 5 for blacks are based on the variation among the 23 half-samples that did achieve convergence. If these half-samples were selected randomly, the estimated standard errors would be consistent, but inefficient estimates of the true standard errors.

\section{d. Microsimulation techniques for hazard model results}

To interpret the estimated coefficients for the exit and re-entry probabilities in terms of the number of years spent in poverty, I next employ microsimulation techniques similar to those used in Moffitt and Rendall (1993) and Gottschalk and Moffitt (1994). The logit hazard rates specified above can be expressed in terms of the underlying latent index functions.

$$
\begin{aligned}
& I^{p}=\theta_{i}^{p}+\alpha_{d}^{p}+\beta^{p} X_{i t}+\varepsilon{ }^{p} \\
& I^{n}=\theta_{i}^{n}+\alpha_{d}^{n}+\beta^{n} X_{i t}+\varepsilon^{n}
\end{aligned}
$$

The terms $I^{p}$ and $I^{n}$ represent latent variables such that an exit from the indicated state (poverty or non-poverty) occurs if the value is greater than zero, and no exit occurs otherwise.

The error terms, $\varepsilon^{p}$ and $\varepsilon^{n}$ are assumed to be distributed independently and to follow the logistic distribution.

Given estimates of $\theta, \alpha$, and $\beta$, the above equations can be used to simulate the distribution of time spent below the poverty line for a group of individuals just falling into poverty. The error terms are generated by random draws from the logistic distribution. Values 
for $\theta^{p}$ and $\theta^{n}$ are included in these simulations by drawing values from discrete distributions with the estimated support points and probabilities shown in Table 5. Using the estimated coefficients on observable characteristics, multi-year sequences of poverty status are simulated for 10,000 individuals just beginning a poverty spell and with a specified starting age, sex of household head, and education of household head. An exit occurs if $I^{p}$ is greater than zero, and in the next period the possibility of returning to poverty is simulated in the same fashion.

Table 6 shows the importance of variation in individual and family characteristics for poverty persistence. For two age groups beginning a stay in poverty at birth, and at age 20 , mean time in poverty and the percentage spending more than half of the next ten years poor are shown by sex and education of the household head. This table illustrates that this small set of characteristics accounts for a great deal of variation in poverty persistence. Among children, shown in the upper portion of the table, for example, the mean years poor varies from 3.25 out of the next ten for whites in a household headed by a male with at least a high school education to 8.3 of the next ten for blacks in a female-headed household with less than a high school education. Poverty is an extremely persistent state for those in female-headed households, and those in households where the head does not have a high school education. Nearly 90 percent of black children in the low-education, female-head category who fall below the poverty line will be poor for six or more of the next ten years.

The effects of female headship shown in Table 6 are large, but this is partially a function of the simulation being performed in this table. The contrast between male- and female-headed households is between individuals remaining in a male- or female-headed household over the entire ten year period. In the case of female headship, in particular, holding constant headship 
status over such a lengthy period may not be realistic. Distributions can also be calculated based on alternative profiles of female headship over the period. Suppose, for example, that a child is born into poverty and spends only the first three years of life in a female-headed household, and the following seven years in a two parent household. The estimated average time spent in poverty in this case is 5.2 years for whites (where the head has less than a high school education) and 7.0 years for blacks. This can be compared with 4.0 years and 6.0 years among children who spend no time in a female-headed family. Even a relatively short time period spent in a femaleheaded household significantly increases poverty persistence.

\section{A components-of-variance approach to the measurement of poverty persistence}

As noted in section I an alternative approach used to study poverty dynamics is the estimation of parameters of a time series process describing earnings or income dynamics. These estimated parameters can then be used to derive statements about poverty persistence. In this section I implement such an approach and compare the results to those from the hazard model.

Components-of-variance models were first used to study poverty or low-earnings status by Lillard and Willis (1978). Since that time many variations of this basic approach have appeared in the literature. The implementation here differs somewhat from much previous work in that the dependent variable used is the $\log$ of the income-to-needs ratio, rather than individual earnings or income. Duncan (1983) and Duncan and Rodgers (1991) have estimated these models directly for the income-to-needs ratio, and I follow their approach here. Another difference from Lillard and Willis and some other authors involves the estimation method. Recently components-of-variance models have been estimated not by maximum likelihood, but by a generalized method-of-moments approach that minimizes the distance between the sample 
covariances and their population counterparts (Abowd and Card, 1989, Baker, 1995). The newer approach avoids the previous literature's assumption that the variance components are normally distributed. I use this approach and estimate the variance components using an equally weighted minimum distance estimator. 19

Initially following Lillard and Willis' (1978) model for individual earnings, suppose that the evolution of the income-to-needs ratio over time can be summarized by the following equations:

$$
\begin{aligned}
& Y_{i t}=X_{i t} \beta+\varepsilon_{i t} \\
& \varepsilon_{i t}=\alpha_{i}+u_{i t} \\
& u_{i t}=\rho u_{i, t-1}+v_{i t}
\end{aligned}
$$

$Y_{i t}$ is the $\log$ of the income-to-needs ratio; $X_{i t}$ contains terms for age and year effects (and potentially other variables); and the error term consists of a person-specific component $\left(\alpha_{i}\right)$ and a transitory term that follows an AR(1) pattern.

The model summarized by (15)-(17) implies a particular form for the covariances of $\varepsilon_{i t}$. Specifically,

$$
\begin{aligned}
\operatorname{cov}\left(\varepsilon_{i t}, \varepsilon_{i s}\right)= & \operatorname{var}\left(\alpha_{i}\right)+\frac{\rho^{|t-s|}}{1-\rho^{2}} \operatorname{var}\left(\mathrm{v}_{\mathrm{it}}\right) \\
= & \sigma_{\alpha}^{2}+\frac{\rho^{|t-s|}}{1-\rho^{2}} \sigma_{v}^{2}
\end{aligned}
$$

19 This estimator will provide consistent, but asymptotically inefficient, estimates of the parameters. The asymptotically efficient estimator uses the inverse of the consistently estimated variance-covariance matrix of the second moments as a weighting matrix. It has been common in the recent literature, however, to use the identity matrix (or equal weights) instead. This is because of the potential singularity of the estimated variance-covariance matrix, and its poor small sample properties (Baker, 1995). Abowd and Card (1989) show that the optimally weighted estimator may produce misleading estimates, particularly in the case of relatively poor-fitting models. 
The unique elements of the population covariance matrix can be represented by the column vector $f\left(\sigma_{\alpha}^{2}, \rho, \sigma_{v}^{2}\right)$. Let the elements of the estimated covariance matrix be similarly arrayed into a column vector $c$. The parameters of the model are estimated by minimizing

$$
\left(c-f\left(\sigma_{\alpha}^{2}, \rho, \sigma_{v}^{2}\right)\right)^{\prime}\left(c-f\left(\sigma_{\alpha}^{2}, \rho, \sigma_{v}^{2}\right)\right)
$$

with respect to $\sigma_{\alpha}^{2}, \rho$ and $\sigma_{v}^{2} .20$

The estimated covariance matrix is shown in Table 7. This matrix was formed from the residuals of separate regressions by year of the log income-to-needs ratio on age and age squared. 21 For comparability with the hazard model results, controls were also included for race, education and whether the household was headed by a single female. The sample used is restricted to adults between the ages of 24 and 64, and present in every year from 1969 through 1988. The diagonal terms in Table 7 show the cross-sectional variances in each year from 1969 through 1988. The terms above the diagonal are correlation coefficients, and the covariances are shown below the diagonal. This table shows an increase in the cross-sectional variances over time, particularly during the 1980 s, and substantial persistence in the covariance terms at higher orders.

The estimated parameters of the error structure are shown in Table 8. The first model estimated is that specified above, with an individual effect and a transitory term that follows an AR(1) process. An obvious shortcoming of this model is that it predicts constant variances over

20 In practice, there is one additional parameter to estimate, representing the accumulation of the error term prior to 1969.

21 The sample contains the non-random portion of the PSID and so both the first-stage regressions and the calculation of the covariances use sample weights. I have also performed the analysis using only the random sample portion of the PSID without weights and obtained similar results. Lillard and Willis (1978) and Baker (1995) use only the random portion of the PSID. Abowd and Card (1989) show results for samples with and without the nonrandom portion, and find the two to be similar, as I do here. 
time. This, however, is inconsistent with the estimated covariance matrices. A simple way to accommodate the non-stationarity of the variances is to allow the transitory term $\left(v_{i t}\right)$ to have year-specific variances. The parameters of this model are shown in the second row of the table. The third and fourth rows of the table contain results from a model that contains an individualspecific slope, as well as the individual-specific intercept. This type of model was originally proposed for earnings by Hause (1977), and is also used in Lillard and Weiss (1979) and Baker (1995). In this model equation (16) above is replaced with

$$
\varepsilon_{i t}=\alpha_{i}+\lambda_{i} a g e_{i t}+u_{i t} .
$$

The final model estimated allows the transitory component of log income-to-needs to follow an $\operatorname{ARMA}(1,1)$ process, with a moving average parameter $\theta$ along with the autoregressive parameter $\rho$. The introduction of a moving average component is suggested by the work of Abowd and Card (1989), who find evidence of serially uncorrelated measurement error in earnings. The inclusion of a moving average component here will capture a purely transitory component of the variance structure, possibly due to measurement error in the incometo-needs ratio, and may help to fit the relatively sharp decline in the estimated covariances at the first order.

The variance of the individual-specific slope term is statistically significant in all cases. The estimates (from row three) of the variance of $\lambda$ and the covariance of $\alpha$ and $\lambda$ predict an increase in the cross-sectional variances of .14 from 1969 through 1988, capturing some of the observed increase in the variances over time. Allowing the transitory component to vary across years has relatively minor effects on the other estimated parameters. 
The final two rows of Table 8 show the results of allowing for a moving average component in the transitory variance. These results show a small, negative estimated value for $\theta$, consistent with the patterns in the estimated covariance matrix. The specification including an $\operatorname{ARMA}(1,1)$ component was somewhat sensitive to starting values, particularly when the model was estimated with a constant transitory variance. 22

I next use the estimates in Table 8 to derive the expected time spent below the poverty line. To do this, I simulate the distribution of log income-to-needs, using the estimated variance components. I generate up to 20 years of data for individuals starting the period at age 30,23 assuming normal distributions for $\mathrm{v}_{\mathrm{it}}$ and $\alpha_{i}$. In the simulations based on models including an individual-specific slope, I assume that $\alpha$, and $\lambda$, follow a bivariate normal distribution with the estimated variances and covariance. These simulations hold business cycle conditions constant at the average of the calendar year terms from the regression of the income-to-needs ratio on age and year. This generates a set of 20 year profiles of the income-to-needs ratio.

Because the hazard rate estimates refer to a flow-based distribution--the distribution of times poor for those just beginning a poverty spell--the predictions from the components-ofvariance models must be presented in a similar form. The simulated data can be used to answer the same question as the hazard model--what is the distribution of total years poor over the next $\mathrm{S}$ years for individuals just starting a poverty spell? This is achieved by identifying individuals'

22 In particular, the estimation was sensitive to the starting value for the moving average parameter, converging to a negative value of $\theta$ only when the starting value was negative, and converging to a positive value otherwise, with the resulting values for the distance function very close to one another. This is less of a problem in the model with year-specific variances, although the model shown in row (6) of Table 8 remains somewhat sensitive to the starting values for $\theta$.

23 An alternative would be to condition on the actual age distribution in the sample. I use a cohort beginning the period at a particular age for comparisons with the results of the hazard model. 
first entrance into poverty during the simulated period. These individuals are then followed over the next ten years, and the resulting total times in poverty calculated. Simulations were run based on several of the models shown in Table 8; the results discussed below are based on the results shown in row five of the table. 24

As with the hazard models. I perform this exercise for eight demographic groups based on whether the household is headed by a female, the education of the household head, and race. Resulting distributions of time spent in poverty over the next ten years by persons just beginning a poverty spell are shown in columns two and five of Table 9. For comparison, the table includes corresponding estimates from the hazard model and estimates from directly tabulating total time poor for a cohort of individuals observed entering poverty. 25 A complication for the "direct tabulation" results is that once covariates have been introduced into the model, sample sizes for the direct tabulations are dramatically reduced. In order to increase sample sizes, the direct tabulation figures are based on all adults entering poverty, with the given characteristics and aged 20 to 55. The results in Table 9 are for household heads with less than a high school education; in the interest of brevity results for those with more education are not shown, but the comparisons for the more educated groups are similar.

Table 9 shows that the consistency of results from the three models differs across demographic groups. I focus first on the results for individuals in male headed households. Among blacks the three distributions are similar, and result in a mean time in poverty over the next ten years of 4.3 to 4.5 years. In the results for whites, the variance components model

24 Results based on row six of the table, including individual-specific slopes, were similar. However, given the sensitivity of this model to starting values, I have used the slightly simpler specification shown in row nine for the reported simulation results.

25 The hazard model results here differ from those reported in the lower portion of Table 6 only by the starting age, which is 30 in this case. 
predicts somewhat longer stays in poverty than the other two techniques. The average time in poverty is estimated at 4 years by this method, compared to 3.1 or 3.2 years from the hazard model and direct tabulations. The variance components model also predicts substantially longer stays in poverty than the other two methods among more educated blacks and whites.

For individuals in households headed by females, the comparison across methods is less straightforward. To increase sample sizes the direct tabulation results for female-headed households include individuals spending six or more out of ten years with a female head. Thus, I expect the hazard and variance components models to predict longer stays in poverty, since these simulations assume the individual remains in a female-headed household for the entire ten year period. For black female heads, however, the variance components model actually predicts a shorter average stay in poverty ( 5 years) than the direct tabulations ( 6.2 years). The hazard model estimates suggest longer stays in poverty than the other two methods. Among black female heads, the hazard rate and direct tabulation methods result in similar distributions of time in poverty; the major difference between the two is that the hazard estimates show fewer individuals spending only one year below the poverty line. Among white female heads, the three methods all result in rather different distributions. The relatively small sample size for the direct tabulations for this group makes it difficult to draw any strong conclusions, but neither the hazard or component-of-variance results are close to the tabulated distribution.

At least in the results for male-headed households, the hazard model captures observed patterns of poverty persistence somewhat better than the variance components model. For individuals in male-headed households, the expected times in poverty based on the hazard model and direct tabulations are remarkably similar, while the variance components model, on average, 
substantially overstates expected times in poverty. Several factors may explain the discrepancies between results from the two modeling strategies. One possibility is that the variance components models estimated do not adequately fit the sample covariances. For evidence on this possibility, I compared the predicted and actual correlations of income-to-needs across years. Actual correlations of income-to-needs ratios at orders one through five are $.81, .74, .70, .66$, and .63. The predicted values of the correlations are almost identical at $.81, .73, .70, .65$, and .62 . All of the predicted and actual correlations are very close, except for those 15 or more years apart. It seems unlikely that problems with the fit of the model are a key factor in the discrepancies.

Another possibility is that the variance components model estimated on a pooled sample of all adults is not flexible enough to capture different dynamic patterns across groups. In the current framework, only differences in mean income-to-needs ratios are driving the differences across groups, since a common variance structure is estimated for the entire sample. To investigate this possibility, the variance components model was estimated for a sample restricted to white male heads. The hazard model was similarly re-estimated on a sample of white male heads of household. The results, and the comparison between the two models, were qualitatively the same as those discussed above. In particular, the variance components model predicted longer stays in poverty, and a substantially smaller proportion of individuals experiencing single year stays in poverty.

A final point to note is that the components-of-variance approach is based on estimation of parameters describing the full distribution of income (or specifically the income-to-needs ratio) while the hazard model is based on samples of individuals with income-to-needs below the 
poverty line at some point. Thus, it is not surprising that the hazard model better replicates observed patterns at the low end of the distribution. It is possible that income dynamics below the mean of the distribution are different than those at or above the mean. Conventional variance components models, however, assume that the same dynamic patterns operate over all ranges of the income distribution. If shocks that move individuals below the poverty line differ in important ways from positive or smaller negative shocks, poverty dynamics may not be well captured by standard time-series models. 26

Overall, these comparisons suggest that the hazard model developed here comes close to replicating the distributions of time in poverty from a relatively simple method of directly tabulating years in poverty from the panel data. There is some need for caution implied by differences in the hazard and tabulation results for female household heads, although these comparisons are complicated by the small sample sizes available for the tabulation results. The components-of-variance approach seems to over-estimate time in poverty among male household heads, and may under-estimate time poor among female household heads. While the three methods yield similar results, these discrepancies suggest that attention to the accuracy of variance-component models in predicting dynamic patterns near the bottom of the income distribution may be an important area for further research.

26 Similar issues, relating to the appropriateness of linear ARMA processes, have been discussed in the macroeconomics literature. Neftci (1984) and Sichel (1993) offer evidence of asymmetries in macroeconomic series, and show that these asymmetries are missed by standard ARMA models. Hamilton (1989) builds a model in which a time-series process is subject to discrete regime shifts over time. The hazard rate analysis presented here provides some clues that similar issues could be important with respect to poverty dynamics. Differences in the types of events associated with beginning versus ending poverty spells, for example, suggest that asymmetries may play a role in poverty dynamics. The importance of household composition changes in moving individuals into poverty suggests that a model incorporating regime changes into the income process might be usefully applied to poverty or household income dynamics as well. 


\section{Conclusion}

Poverty persistence, as measured by the expected time poor for individuals currently starting a stay in poverty, is much greater than that predicted by previous work on single spells. Bane and Ellwood (1986) emphasized the substantial persistence of poverty that results from looking at the stock of persons poor at any point in time. They contrasted this with the lesser persistence in the flow measure--the expected time spent poor for an individual just beginning a poverty spell. My findings demonstrate that even flow-based distributions of time spent below the poverty line suggest substantial poverty persistence once re-entry probabilities and multiple spells are considered.

Predicted times in poverty from the hazard model have also been compared with predictions from two other methods. Estimates from direct tabulations and from the hazard model are generally in agreement, although small sample sizes available for the tabulation methods complicate this comparison for certain groups. For most of the demographic groups examined, however, the two methods yield similar results in terms of both average times in poverty over some period and in terms of the complete distribution of years poor. Estimation of components-of-variance models of the income-to-needs ratio provides a third method for evaluating the persistence of poverty. Results from these models for individuals in male-headed households indicate more persistence in poverty than either the hazard model or direct tabulations. Predictions from these models are generally less consistent with observed patterns of poverty dynamics than are those from the hazard models.

All of the results presented here show that reliance on single-spell measures of poverty persistence significantly overstate the degree of mobility out of poverty. Recent work by 
Gottschalk, McLanahan, and Sandefur (1994, p. 90) highlights the observation that "most lowincome people, including most blacks, will be poor for less than two years." This is true in the sense that most will then experience at least a single year out of poverty, but looking at total time in poverty over the next decade paints a different picture. Average time in poverty over the next ten years from Table 2 is over four years; more than half of all blacks and around one third of whites falling into poverty will spend five or more of the next ten years in poverty.

The question of whether poverty is a transitory or a permanent state largely depends on characteristics of individuals and their families. Individuals in male-headed households experience the most transient poverty, with education and race also playing an important role in predicting stays below the poverty line. The average stay in poverty over the next ten years for those in households headed by black, less educated males is approximately four years; for those in households headed by whites with at least a high school education the average stay is less than two and a half years. For individuals in households where the head is a single female, or has less than a high school education, poverty is an extremely persistent state. Among adults in femaleheaded households who fall below the poverty line, between 26 and 64 percent (depending on race and education level) will live below the poverty line for six or more of the next ten years. Among children in female-headed households the comparable figures range from $\$ 7$ to nearly 90 percent. The conventional view that most individuals falling into poverty experience very short spells should be modified to account for the frequency and importance of multiple episodes with income below the poverty line. 
Table 1

Exit and Re-entry Rates by Duration and Race 1969-1988

\begin{tabular}{|l|c|c|c|c|c|c|c|}
\hline & \multicolumn{3}{|c|}{ Exit Rates } & & \multicolumn{3}{c|}{ Re-entry Rates } \\
\hline $\begin{array}{l}\text { Duration } \\
\text { (years) }\end{array}$ & All & Blacks & Whites & & All & Blacks & Whites \\
\hline 1 & .53 & .42 & .57 & & .27 & .35 & .23 \\
& $(.011)$ & $(.017)$ & $(.013)$ & & $(.010)$ & $(.017)$ & $(.011)$ \\
\hline 2 & .36 & .32 & .38 & & .16 & .23 & .14 \\
& $(.014)$ & $(.021)$ & $(.019)$ & & $(.010)$ & $(.020)$ & $(.011)$ \\
\hline 3 & .27 & .20 & .31 & & .11 & .13 & .10 \\
& $(.016)$ & $(.017)$ & $(.025)$ & & $(.009)$ & $(.013)$ & $(.012)$ \\
\hline 4 & .23 & .17 & .27 & & .09 & .11 & .08 \\
& $(.014)$ & $(.026)$ & $(.022)$ & & $(.007)$ & $(.016)$ & $(.010)$ \\
\hline 5 & .19 & .15 & .22 & & .08 & .10 & .07 \\
& $(.020)$ & $(.022)$ & $(.028)$ & & $(.008)$ & $(.015)$ & $(.009)$ \\
\hline 6 & .16 & .13 & .19 & & .07 & .12 & .05 \\
& $(.018)$ & $(.024)$ & $(.024)$ & & $(.008)$ & $(.025)$ & $(.011)$ \\
\hline 7 & .15 & .15 & .15 & & .06 & .05 & .06 \\
& $(.029)$ & $(.036)$ & $(.040)$ & & $(.009)$ & $(.011)$ & $(.011)$ \\
\hline 8 & .13 & .08 & .17 & & .04 & .04 & .04 \\
& $(.022)$ & $(.014)$ & $(.045)$ & & $(.010)$ & $(.008)$ & $(.013)$ \\
\hline 9 & .12 & .08 & .16 & & .05 & .07 & .05 \\
& $(.022)$ & $(.022)$ & $(.046)$ & & $(.009)$ & $(.029)$ & $(.009)$ \\
\hline 10 & .11 & .10 & .12 & & .04 & .04 & .04 \\
& $(.015)$ & $(.018)$ & $(.035)$ & & $(.004)$ & $(.007)$ & $(.005)$ \\
\hline
\end{tabular}

Standard error of hazard rate in parentheses. 
Table 2

Distribution of Years in Poverty--Single Spells and Multiple Spells

\begin{tabular}{|c|c|c|c|}
\hline $\begin{array}{l}\text { Years in } \\
\text { poverty }\end{array}$ & $\begin{array}{l}\text { Distribution of } \\
\text { single spells }\end{array}$ & $\begin{array}{l}\text { Distribution of } \\
\text { years poor out of } \\
\text { next } 10 \text {--simulated }\end{array}$ & $\begin{array}{l}\text { Distribution of } \\
\text { years poor out of } \\
\text { next 10--actual }\end{array}$ \\
\hline & \multicolumn{3}{|c|}{ Total Sample } \\
\hline 1 & 52.5 & 17.5 & 29.5 \\
\hline 2 & 17.2 & 15.5 & 14.7 \\
\hline 3 & 8.2 & 13.9 & 11.7 \\
\hline 4 & 5.0 & 11.9 & 9.3 \\
\hline 5 & 3.2 & 9.8 & 6.2 \\
\hline 6 & 2.2 & 7.8 & 7.3 \\
\hline 7 & 1.8 & 6.4 & 5.5 \\
\hline 8 & 1.2 & 5.2 & 5.0 \\
\hline 9 & 1.0 & 4.4 & 5.7 \\
\hline \multirow[t]{3}{*}{10} & 7.7 & 7.6 & 5.2 \\
\hline & 100.0 & 100.0 & 100.0 \\
\hline & \multicolumn{3}{|c|}{ Blacks } \\
\hline 1 & 41.8 & 9.9 & 17.7 \\
\hline 2 & 18.5 & 9.8 & 10.8 \\
\hline 3 & 8.0 & 10.1 & 10.5 \\
\hline 4 & 5.4 & 10.6 & 7.5 \\
\hline 5 & 3.9 & 9.9 & 6.8 \\
\hline 6 & 2.9 & 9.5 & $\overline{9.4}$ \\
\hline 7 & 2.9 & 9.3 & 7.4 \\
\hline 8 & 1.4 & 8.8 & 8.1 \\
\hline 9 & 1.2 & 7.8 & 10.7 \\
\hline \multirow[t]{3}{*}{10} & 14.0 & 14.0 & 11.0 \\
\hline & 100.0 & 100.0 & 100.0 \\
\hline & \multicolumn{3}{|c|}{ Whites } \\
\hline 1 & 57.0 & 21.3 & 33.8 \\
\hline 2 & 16.6 & 18.1 & 16.0 \\
\hline 3 & 8.2 & 15.2 & 12.2 \\
\hline 4 & 4.9 & 12.1 & 10.0 \\
\hline 5 & 3.0 & 9.4 & 5.9 \\
\hline 6 & 1.9 & 6.9 & 6.5 \\
\hline 7 & 1.3 & 5.1 & 4.8 \\
\hline 8 & 1.2 & 3.9 & 3.9 \\
\hline 9 & 0.9 & 3.2 & 3.9 \\
\hline 10 & 5.0 & 5.0 & 3.9 \\
\hline & 100.0 & 100.0 & 100.0 \\
\hline
\end{tabular}


Table 3

Exit Rate Logit Coefficients by Race

\begin{tabular}{|c|c|c|c|c|c|c|}
\hline Duration & \multicolumn{2}{|c|}{ All } & \multicolumn{2}{|c|}{ Blacks } & \multicolumn{2}{|c|}{ Whites } \\
\hline 1 & .32 & $(.14)$ & .08 & $(.23)$ & .40 & $(.15)$ \\
\hline 2 & -.32 & (.18) & -.28 & $(.28)$ & \begin{tabular}{|c|}
.35 \\
\end{tabular} & $(.19)$ \\
\hline 3 & -.76 & $(.16)$ & -.83 & $(.26)$ & \begin{tabular}{|c|}
-.73 \\
\end{tabular} & $(.17)$ \\
\hline 4 & -.94 & (.19) & -1.06 & $(.33)$ & 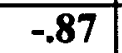 & (.19) \\
\hline 5 & -1.13 & (.18) & -1.21 & $(.28)$ & \begin{tabular}{|c|}
-1.07 \\
\end{tabular} & $(.21)$ \\
\hline 6 & -1.29 & $(.20)$ & -1.34 & $(.29)$ & \begin{tabular}{|c|}
-1.19 \\
\end{tabular} & $(.22)$ \\
\hline 7 & -1.34 & $(.23)$ & -1.20 & $(.31)$ & \begin{tabular}{|l|}
-1.44 \\
\end{tabular} & $\overline{(.31)}$ \\
\hline 8 & -1.49 & $(.24)$ & -1.87 & $(.30)$ & \begin{tabular}{|l|}
-1.21 \\
\end{tabular} & $(.36)$ \\
\hline 9 & -1.56 & $(.28)$ & -1.82 & $(.37)$ & \begin{tabular}{|l|}
-1.31 \\
\end{tabular} & $(.44)$ \\
\hline $\begin{array}{l}10 \text { or } \\
\text { more }\end{array}$ & -1.68 & $(.21)$ & -1.63 & $(.30)$ & -1.64 & $(.39)$ \\
\hline \multicolumn{7}{|l|}{ Year } \\
\hline 69 & -.21 & $(.40)$ & .72 & $(.38)$ & -.72 & $(.57)$ \\
\hline 70 & .24 & $(.25)$ & .49 & (.39) & .13 & $(.31)$ \\
\hline 71 & .49 & $(.23)$ & .48 & $(.36)$ & .49 & $(.28)$ \\
\hline 72 & .31 & $(.20)$ & -.20 & $(.36)$ & .47 & $(.21)$ \\
\hline 73 & .55 & $(.20)$ & .32 & $(.35)$ & .69 & $(.24)$ \\
\hline 74 & .23 & $(.20)$ & .19 & $(.29)$ & .26 & $(.25)$ \\
\hline 75 & -.23 & $(.18)$ & -.17 & $(.30)$ & \begin{tabular}{ll|}
-.24 \\
\end{tabular} & $(.20)$ \\
\hline 76 & .37 & $(.21)$ & .11 & $(.36)$ & .52 & $(.23)$ \\
\hline 77 & .02 & $(.21)$ & -.23 & $(.27)$ & .14 & $(.21)$ \\
\hline 78 & .20 & $(.18)$ & .17 & $(.29)$ & .23 & $(.20)$ \\
\hline 79 & .27 & $(.20)$ & .23 & $(.25)$ & .29 & $(.26)$ \\
\hline 80 & -.34 & $(.20)$ & -.23 & $(.31)$ & -.40 & $(.22)$ \\
\hline 81 & -.24 & $(.19)$ & -.73 & $(.32)$ & -.06 & $(.23)$ \\
\hline 82 & -.39 & $(.16)$ & -.47 & $(.25)$ & -.36 & $(.17)$ \\
\hline 83 & -.22 & $(.15)$ & -.48 & $(.24)$ & \begin{tabular}{ll|}
-.11 \\
\end{tabular} & $(.16)$ \\
\hline 84 & .12 & $(.19)$ & -.02 & $(.26)$ & .19 & $(.20)$ \\
\hline 85 & -.21 & $(.15)$ &.- .33 & $(.23)$ & -.14 & $(.21)$ \\
\hline 86 & -.00 & $(.19)$ &.- .31 & $(.29)$ & .13 & $(.19)$ \\
\hline 87 & -.10 & $(.18)$ & -.36 & $(.31)$ & .01 & $(.18)$ \\
\hline
\end{tabular}


Table 3 (cont'd)

Exit Rate Logit Coefficients by Race

\begin{tabular}{|l|r|r|r|r|r|r|r|r|}
\hline & \multicolumn{2}{|c|}{ All } & \multicolumn{2}{c|}{ Blacks } & \multicolumn{2}{c|}{ Whites } \\
\hline Age & & & & & & & & \\
\hline $0-5$ & -.43 & $(.06)$ & & -.48 & $(.11)$ & & -.33 & $(.06)$ \\
\hline $6-12$ & $\mathbf{- 2 0}$ & $(.06)$ & & -.24 & $(.06)$ & & -.19 & $(.07)$ \\
\hline $13-17$ & -.15 & $(.08)$ & & -.12 & $(.08)$ & & -.15 & $(.11)$ \\
\hline $18-24$ & .22 & $(.05)$ & & .28 & $(.10)$ & & .20 & $(.24)$ \\
\hline $34-44$ & .03 & $(.09)$ & & .16 & $(.14)$ & & -.03 & $(.09)$ \\
\hline $45-54$ & .12 & $(.07)$ & & .07 & $(.12)$ & & .11 & $(.10)$ \\
\hline $\begin{array}{l}55 \text { or } \\
\text { older }\end{array}$ & -.19 & $(.08)$ & & .03 & $(.16)$ & & -.35 & $(.10)$ \\
\hline & & & & & & & \\
\hline $\begin{array}{l}\text { Education } \\
>=12\end{array}$ & .39 & $(.07)$ & .44 & $(.11)$ & & .33 & $(.08)$ \\
\hline $\begin{array}{l}\text { Female } \\
\text { head }\end{array}$ & -.77 & $(.07)$ & -.81 & $(.11)$ & & $\mathbf{. 6 3}$ & $(.08)$ \\
\hline
\end{tabular}

Standard errors of logit coefficients in parentheses. 
Table 4

Re-entry Rate Logit Coefficients by Race

\begin{tabular}{|c|c|c|c|c|c|c|}
\hline Duration & \multicolumn{2}{|c|}{ All } & \multicolumn{2}{|c|}{ Blacks } & \multicolumn{2}{|c|}{ Whites } \\
\hline 1 & $\begin{array}{l}-1.43 \\
\end{array}$ & (.09) & -1.16 & $(.22)$ & -1.57 & $(.13)$ \\
\hline 2 & -2.07 & $(.13)$ & -1.69 & $(.23)$ & -2.25 & $(.15)$ \\
\hline 3 & -2.42 & (.13) & -2.29 & $(.23)$ & -2.49 & $(.17)$ \\
\hline 4 & -2.66 & (.12) & $\begin{array}{l}-2.48 \\
\end{array}$ & $(.23)$ & -2.74 & $(.18)$ \\
\hline 5 & -2.80 & (.10) & -2.50 & $(.18)$ & -2.93 & $(.15)$ \\
\hline 6 & -2.96 & (.13) & -2.36 & $(.23)$ & -3.25 & $(.23)$ \\
\hline 7 & -3.05 & (.17) & -3.23 & $(.24)$ & -3.03 & $(.20)$ \\
\hline 8 & -3.38 & $(.20)$ & -3.34 & $(.22)$ & -3.41 & $(.26)$ \\
\hline 9 & -3.13 & (.16) & -2.77 & $(.44)$ & $\begin{array}{l}-3.30 \\
\end{array}$ & $(.19)$ \\
\hline $\begin{array}{l}10 \text { or } \\
\text { more }\end{array}$ & -3.49 & $(.13)$ & -3.44 & $(.20)$ & -3.53 & $(.16)$ \\
\hline \multicolumn{7}{|l|}{ Year } \\
\hline 69 & -.97 & $(.28)$ & -1.06 & $(.35)$ & -.89 & $(.40)$ \\
\hline 70 &.- .33 & $(.24)$ & -.35 & $(.30)$ & -.31 & $(.40)$ \\
\hline 71 & .02 & $(.24)$ & -.06 & $(.34)$ & .08 & $(.28)$ \\
\hline 72 & -.26 & $(.15)$ & .14 & $(.25)$ & -.49 & $(.18)$ \\
\hline 73 & -.39 & $(.14)$ & -.45 & $(.26)$ & -.31 & $(.20)$ \\
\hline 74 & .35 & $(.14)$ & .40 & $(.21)$ & .34 & $(.20)$ \\
\hline 75 & .05 & $(.13)$ & .24 & $(.23)$ & -.07 & $(.19)$ \\
\hline 76 & .00 & $(.14)$ & .07 & $(.24)$ & -.01 & $(.19)$ \\
\hline 77 & -.11 & $(.16)$ & .27 & $(.25)$ & -.28 & $(.19)$ \\
\hline 78 & -.09 & $(.15)$ & .03 & $(.21)$ & -.12 & $(.17)$ \\
\hline 79 & -.11 & $(.15)$ & -.20 & $(.25)$ & -.07 & $(.20)$ \\
\hline 80 & .15 & $(.13)$ & .06 & $(.23)$ & .18 & $(.17)$ \\
\hline 81 & .21 & $(.15)$ & .14 & $(.26)$ & .25 & $(.18)$ \\
\hline 82 & .32 & $(.14)$ & .38 & $(.24)$ & .31 & $(.18)$ \\
\hline 83 & .15 & $(.13)$ & .33 & $(.15)$ & .08 & $(.18)$ \\
\hline 84 & .03 & $(.11)$ & .43 & $(.18)$ & -.09 & $(.14)$ \\
\hline 85 & .20 & $(.13)$ & .04 & $(.24)$ & .06 & $(.16)$ \\
\hline 86 & -.06 & $(.14)$ & -.06 & $(.25)$ & -.06 & $(.17)$ \\
\hline 87 & -.13 & $(.16)$ & .14 & $(.19)$ & -.21 & $(.20)$ \\
\hline
\end{tabular}


Table 4 (cont'd)

Re-entry Rate Logit Coefficients by Race

\begin{tabular}{|c|c|c|c|c|c|c|}
\hline \multirow{2}{*}{ Age } & \multicolumn{2}{|c|}{ All } & \multicolumn{2}{|c|}{ Blacks } & \multicolumn{2}{|c|}{ Whites } \\
\hline & & & & & & \\
\hline $0-5$ & .61 & $(.08)$ & .59 & $(.10)$ & .59 & $(.11)$ \\
\hline $6-12$ & .48 & $(.07)$ & .38 & $(.09)$ & .52 & $(.09)$ \\
\hline $13-17$ & .47 & $(.08)$ & .33 & $(.15)$ & .52 & $(.09)$ \\
\hline $18-24$ & .18 & $(.06)$ & .09 & $(.10)$ & .20 & $\begin{array}{l}(.09) \\
\end{array}$ \\
\hline $34-44$ & .17 & $(.07)$ & .01 & $(.15)$ & .23 & $(.08)$ \\
\hline $45-54$ & .14 & $(.10)$ & -.16 & $(.15)$ & .26 & $(.12)$ \\
\hline $\begin{array}{l}55 \text { or } \\
\text { older }\end{array}$ & .32 & $(.07)$ & .12 & $(.11)$ & .46 & $(.08)$ \\
\hline & & & & & & \\
\hline $\begin{array}{l}\text { Education } \\
>=12\end{array}$ & -.38 & $(.06)$ & -.56 & (.11) & -.28 & $(.08)$ \\
\hline $\begin{array}{l}\text { Female } \\
\text { head }\end{array}$ & .74 & $(.07)$ & .86 & $(.09)$ & .61 & $(.08)$ \\
\hline
\end{tabular}

Standard errors of logit coefficients in parentheses. 
Table 5

Coefficients from Maximum Likelihood Estimation of Hazard Rates With Unobserved Heterogeneity

\begin{tabular}{|l|r|r|r|r|r|}
\hline & \multicolumn{2}{|c|}{ Blacks } & & \multicolumn{2}{c|}{ Whites } \\
\hline & $\begin{array}{c}\text { Out of } \\
\text { poverty } \\
\text { spells }\end{array}$ & $\begin{array}{c}\text { Poverty } \\
\text { spells }\end{array}$ & & $\begin{array}{c}\text { Out of } \\
\text { poverty } \\
\text { spells }\end{array}$ & $\begin{array}{c}\text { Poverty } \\
\text { spells }\end{array}$ \\
\hline Duration \\
(years) & & & & & \\
\hline 1 & -1.15 & -.33 & & 1.80 & -1.08 \\
& $(.15)$ & $(.17)$ & & $(.25)$ & $(.18)$ \\
\hline 2 & -1.56 & -.64 & & 1.17 & -1.78 \\
& $(.13)$ & $(.20)$ & & $(.22)$ & $(.19)$ \\
\hline 3 & -2.12 & -1.17 & & .97 & -2.16 \\
& $(.13)$ & $(.21)$ & & $(.26)$ & $(.21)$ \\
\hline 4 & -2.32 & -1.36 & & .77 & -2.24 \\
& $(.19)$ & $(.23)$ & & $(.23)$ & $(.19)$ \\
\hline 5 & -2.24 & -1.49 & & .56 & -2.36 \\
& $(.18)$ & $(.21)$ & & $(.28)$ & $(.25)$ \\
\hline 6 or more & -2.75 & -1.78 & & .20 & -2.62 \\
& $(.10)$ & $(.13)$ & & $(.23)$ & $(.22)$ \\
\hline Age & .72 & -.51 & & .43 & -.36 \\
$<6$ & $(.12)$ & $(.12)$ & & $(.13)$ & $(.10)$ \\
\hline $6-17$ & .36 & -.27 & & .36 & -.14 \\
& $(.06)$ & $(.05)$ & & $(.06)$ & $(.06)$ \\
\hline $18-24$ & -.09 & .25 & & .10 & .20 \\
& $(.06)$ & $(.09)$ & & $(.07)$ & $(.05)$ \\
\hline$>54$ & -.27 & -.14 & & .28 & -.40 \\
& $(.09)$ & $(.16)$ & & $(.08)$ & $(.08)$ \\
\hline Female head & .88 & -.85 & & .68 & -.74 \\
& $(.12)$ & $(.17)$ & & $(.08)$ & $(.10)$ \\
\hline High school or & -1.03 & .27 & & -.26 & .32 \\
more & $(.12)$ & $(.17)$ & & $(.09)$ & $(.06)$ \\
\hline
\end{tabular}


Table 5 (cont'd)

\section{Coefficients from Maximum Likelihood Estimation of Hazard Rates With Unobserved Heterogeneity}

\begin{tabular}{|c|c|c|c|c|}
\hline & $\begin{array}{c}\text { Out of } \\
\text { poverty } \\
\text { spells }\end{array}$ & $\begin{array}{l}\text { Poverty } \\
\text { spells }\end{array}$ & $\begin{array}{c}\text { Out of } \\
\text { poverty } \\
\text { spells }\end{array}$ & $\begin{array}{l}\text { Poverty } \\
\text { spells }\end{array}$ \\
\hline$\overline{\theta_{1}^{p}}$ & & $\begin{array}{r}.85 \\
(.18)\end{array}$ & & $\begin{array}{l}1.66 \\
(.20)\end{array}$ \\
\hline$\theta_{1}^{n}$ & $\begin{array}{l}1.80 \\
(.24)\end{array}$ & & $\begin{array}{r}-3.36 \\
(.21)\end{array}$ & \\
\hline$\theta_{2}^{p}$ & & $0^{*}$ & & $0^{*}$ \\
\hline$\theta_{2}^{n}$ & $0^{*}$ & & $0^{*}$ & \\
\hline $\mathrm{R} 1\left(\theta_{1}^{p}, \theta_{1}^{n}\right)$ & $.00^{1}$ & & $\begin{array}{r}.96 \\
(.04\end{array}$ & \\
\hline $\mathrm{R} 2\left(\theta_{1}^{p}, \theta_{2}^{n}\right)$ & $\begin{array}{r}.44 \\
(.29)\end{array}$ & & .00 & \\
\hline $\mathrm{R} 3\left(\theta_{2}^{p}, \theta_{1}^{n}\right)$ & $\begin{array}{c}.14 \\
(.30)\end{array}$ & & .00 & \\
\hline $\mathrm{R} 4\left(\theta_{2}^{p}, \theta_{2}^{n}\right)$ & $\begin{array}{r}.42 \\
(.30) \\
\end{array}$ & & $\begin{array}{c}.04 \\
(.04\end{array}$ & \\
\hline
\end{tabular}

*This support point is normalized to zero, and a full set of duration dummy variables is included. 'Probabilities for four types of individuals were initially included in the estimation. The indicated probabilities, however, were estimated to be very close to zero. The estimation was then performed restricting the probabilities of these "types" to be equal to zero; this restriction did not affect the other estimated support points or probabilities. 
Table 6

Expected Years in Poverty by Age and by Education and Sex of Household Head

\begin{tabular}{|r|c|c|c|c|c|}
\hline & \multicolumn{2}{|c|}{ Blacks } & \multicolumn{2}{c|}{ Whites } \\
\hline $\begin{array}{l}\text { Mean } \\
\text { years } \\
\text { poor over } \\
\text { next ten }\end{array}$ & $\begin{array}{l}\text { \% poor } \\
\text { more than } \\
\text { five of next } \\
\text { ten years }\end{array}$ & $\begin{array}{l}\text { Mean } \\
\text { years } \\
\text { poor over } \\
\text { next ten }\end{array}$ & $\begin{array}{l}\text { \% poor } \\
\text { more than } \\
\text { five of next } \\
\text { ten years }\end{array}$ \\
\hline $\begin{array}{r}\text { Starting age = 1 } \\
\text { Male household } \\
\text { head }\end{array}$ & & & & & \\
\hline $\begin{array}{r}\text { Less than high } \\
\text { school }\end{array}$ & 5.99 & $55.6 \%$ & & 4.04 & $27.6 \%$ \\
\hline $\begin{array}{r}\text { High school or } \\
\text { more }\end{array}$ & 4.35 & $33.3 \%$ & & 3.25 & $16.7 \%$ \\
\hline $\begin{array}{r}\text { Female } \\
\text { household head }\end{array}$ & & & & & \\
\hline $\begin{array}{r}\text { Less than high } \\
\text { school }\end{array}$ & 8.30 & $89.5 \%$ & & 6.44 & $63.0 \%$ \\
\hline $\begin{array}{r}\text { High school or } \\
\text { more }\end{array}$ & 6.96 & $68.9 \%$ & & 5.41 & $47.3 \%$ \\
\hline $\begin{array}{r}\text { Htarting age = 20 } \\
\text { male household } \\
\text { head }\end{array}$ & & & & & \\
\hline $\begin{array}{r}\text { Less than high } \\
\text { school }\end{array}$ & 3.93 & $26.4 \%$ & & 2.93 & $13.0 \%$ \\
\hline $\begin{array}{r}\text { High school or } \\
\text { more }\end{array}$ & 2.65 & $11.2 \%$ & & 2.42 & $7.7 \%$ \\
\hline $\begin{array}{r}\text { Female } \\
\text { household head }\end{array}$ & & & & & \\
\hline $\begin{array}{r}\text { Less than high } \\
\text { school }\end{array}$ & 6.52 & $64.1 \%$ & & 4.92 & $39.6 \%$ \\
\hline $\begin{array}{r}\text { High school or } \\
\text { more }\end{array}$ & 4.81 & $39.1 \%$ & & 3.99 & $26.4 \%$ \\
\hline
\end{tabular}


Table 7

Estimated Covariance Matrix

\begin{tabular}{|c|c|c|c|c|c|c|c|c|c|c|c|c|c|c|c|c|c|c|c|c|}
\hline & 69 & 70 & 71 & 72 & 73 & 74 & 75 & 76 & 77 & 78 & 79 & 80 & 81 & 82 & 83 & 84 & 85 & 86 & 87 & 88 \\
\hline 69 & 0.265 & 0.786 & 0.708 & 0.640 & 0.652 & 0.619 & 0588 & 0.533 & 0.566 & 0.502 & 0.508 & 0462 & 0438 & 0.428 & 0.404 & 0.389 & 0.335 & 0.337 & 0.345 & 0.333 \\
\hline 70 & 0.217 & 0.288 & 0.806 & 0.739 & 0.739 & 0.618 & 0592 & 0.555 & 0.568 & 0.513 & 0.509 & $0+90$ & $0+39$ & 0.416 & 0.434 & 0.423 & 0.374 & 376 & 0.371 & 356 \\
\hline 71 & 0.214 & 0.254 & 0.345 & 0.756 & 0.750 & 0.666 & 0.611 & 0500 & 0.581 & 0.559 & 0.528 & 0.505 & 0.461 & 0.466 & 0.469 & 0.442 & 0.400 & 0.396 & 0.385 & 370 \\
\hline 72 & 0.183 & 0.220 & 0.247 & 0.308 & 0.848 & 0.714 & 0685 & 0.608 & 0.647 & 0.579 & 0.546 & 0.539 & 0.529 & 0.516 & 0.491 & 0.457 & 0.364 & 0.388 & 0.415 & 0.402 \\
\hline 73 & 0.177 & 0.210 & 0.233 & 0.249 & 0.280 & $0.79^{\circ}$ & 0.715 & 0.668 & 0.681 & 0.642 & 0.605 & 0.577 & 0.552 & 0.517 & 0.488 & 0.466 & 0.409 & 0.418 & 0.417 & 0.406 \\
\hline 74 & 0.184 & 0.192 & 0.226 & 0.229 & 0.244 & 0.335 & 0.765 & 0.716 & 0.731 & 0.688 & 0.635 & 0624 & 0.599 & 0.573 & 0.541 & 0.500 & 0.419 & 0.420 & 0.421 & 0.401 \\
\hline 75 & 0.168 & 0.177 & 0.199 & 0.211 & 0.210 & 0.246 & 0.308 & 0845 & 0.791 & 0.732 & 0.665 & 0.636 & 0.643 & 0.599 & 0.569 & 0.484 & 0.446 & 0.454 & 0.429 & 0.431 \\
\hline 76 & 0.160 & 0.173 & 0.195 & 0.196 & 0.206 & 0.241 & 0.273 & 0.338 & 0.831 & 0.753 & 0.684 & 0.656 & 0.651 & 0.592 & 0.553 & 0.507 & 0.460 & 0.447 & 0.423 & 0.422 \\
\hline 77 & 0.162 & 0.170 & 0.190 & 0.200 & 0.201 & 0.236 & 0.245 & 0.269 & 0.311 & 0.834 & 0.763 & 0.721 & 0.717 & 0.671 & 0.636 & 0.581 & 0.485 & 0.518 & 0.509 & 0.463 \\
\hline 78 & 0.147 & 0.157 & 0.187 & 0.183 & 0.194 & 0.227 & 0.232 & 0.250 & 0.265 & 0.325 & 0.806 & 0.751 & 0.715 & 0.651 & 0.626 & 0.567 & 0.501 & 0.509 & 0.487 & 0.450 \\
\hline 79 & 0.149 & 0.156 & 0.177 & 0.173 & 0.182 & 0.209 & 0.210 & 0.227 & 0.242 & 0.262 & 0.325 & 0809 & 0745 & 0.704 & 0.694 & 0.629 & 0.602 & 0.588 & 0.562 & 0.512 \\
\hline 30 & 0.140 & 0.155 & 0.175 & 0.177 & 0.181 & 0.213 & 0.209 & 0.225 & 0.237 & 0.253 & 0.272 & 0.349 & 0820 & 0719 & 0.670 & 0.603 & 0.550 & 0.566 & 0.503 & 0.512 \\
\hline 81 & 0.148 & 0.154 & 0.178 & 0.193 & 0.192 & 0.227 & 0.234 & 0.248 & 0.262 & 0.268 & 0.278 & 0.318 & 0.430 & 0.776 & 0.726 & 0.659 & 0.563 & 0.574 & 0.550 & 0.520 \\
\hline 82 & 0.157 & 0.159 & 0.195 & 0.204 & 0.195 & 0.236 & 0.237 & 0.245 & 0.266 & 0.264 & 0.286 & 0.302 & 0.362 & 0.507 & 0.774 & 0.671 & 0.597 & 0.620 & 0.634 & 0.562 \\
\hline 83 & 0.145 & 0.163 & 0.193 & 0.191 & 0.181 & 0.219 & 0.221 & 0.225 & 0.248 & 0.250 & 0.277 & 0.277 & 0.333 & 0.385 & 0.489 & 0.776 & 0.729 & 0.699 & 0.666 & 0.561 \\
\hline 34 & 0.143 & 0.162 & 0.185 & 0.180 & 0.176 & 0.206 & 0.191 & 0.210 & 0.231 & 0.230 & 0.255 & 0.254 & 0.308 & 0.340 & 0.386 & 0.507 & 0.755 & 0.688 & 0.643 & 0.566 \\
\hline 85 & 0.128 & 0.150 & 0.175 & 0.150 & 0.161 & 0.181 & 0.185 & 0.199 & 0.202 & 0.213 & 0.255 & 0.242 & 0.275 & 0.316 & 0.380 & 0.401 & 0.555 & 0.775 & 0.675 & 0.589 \\
\hline 86 & 0.114 & 0.133 & 0.153 & 0.142 & 0.146 & 0.100 & 0.166 & 0.171 & 0.190 & 0.191 & 0.220 & 0.220 & 0.248 & 0.290 & 0.322 & 0.322 & 0.380 & 0.434 & 0.780 & 0.664 \\
\hline 37 & 0.128 & 0.143 & 0.163 & 0.166 & 0.159 & 0.175 & 0.171 & 0.177 & 0.204 & 0.200 & 0.230 & 0.214 & 0.259 & 0.325 & 0.335 & 0.330 & 0.362 & 0.370 & 0.518 & 0.785 \\
\hline 8 & 0.115 & 0.128 & 0.146 & 0.150 & 0.144 & 0.155 & 0.161 & 0.165 & 0.173 & 0.172 & 0.195 & 0.203 & 0.229 & 0.268 & 0.263 & 0.270 & 0.294 & 0.293 & 0.378 & 0.450 \\
\hline
\end{tabular}


Table 8

Estimated Variance Components

\begin{tabular}{|c|c|c|c|c|c|c|}
\hline & $\operatorname{Var}(\alpha)$ & $\operatorname{Var}(\lambda)$ & $\begin{array}{c}\operatorname{Cov}(\alpha, \lambda \\
)\end{array}$ & $\theta$ & $\rho$ & $\operatorname{Var}(\varepsilon)$ \\
\hline$(\mathbf{1})$ & .131 & -- & -- & -- & .892 & .061 \\
\hline & $.010)$ & & & & $.008)$ & $(.003)$ \\
\hline$(2)$ & .171 & -- & -- & -- & .836 & varies \\
\hline & $.008)$ & & & & $(.010)$ & \\
\hline$(3)$ & .266 & .000247 & -.0064 & -- & .774 & .085 \\
\hline & $(.054)$ & $(.000044)$ & $(.0035)$ & & $(.020)$ & $(.005)$ \\
\hline$(4)$ & .351 & .000212 & -.0066 & -- & .778 & varies \\
\hline & $(.050)$ & $(.000033)$ & $(.0029)$ & & $(.012)$ & \\
\hline $\mathbf{( 5 )}$ & .158 & -- & -- & -.138 & .880 & varies \\
\hline & $(.008)$ & & & $(.021)$ & $(.007)$ & \\
\hline$(6)$ & .449 & .000202 & -.0077 & -.121 & .860 & varies \\
\hline & $(.069)$ & $(.000041)$ & $(.0039)$ & $. .029)$ & $(.022)$ & \\
\hline
\end{tabular}


Table 9

Comparison of Hazard Rate Estimates, Variance Components Estimates, and Direct Tabulations

\begin{tabular}{|c|c|c|c|c|c|c|}
\hline & \multicolumn{3}{|c|}{ Male head of household } & \multicolumn{3}{|c|}{ Female head of household } \\
\hline poor & \multicolumn{6}{|c|}{ Blacks } \\
\hline & Hazard rate & $\begin{array}{c}\text { Variance } \\
\text { components }\end{array}$ & $\begin{array}{c}\text { Direct } \\
\text { tabulations }\end{array}$ & $\begin{array}{l}\text { Hazard } \\
\text { rate }\end{array}$ & $\begin{array}{c}\text { Variance } \\
\text { components }\end{array}$ & $\begin{array}{c}\text { Direct } \\
\text { tabulations }\end{array}$ \\
\hline 1 & 17.3 & 20.6 & 19.5 & 3.3 & 14.8 & 12.0 \\
\hline 2 & 16.0 & \begin{tabular}{ll|}
14.8 \\
\end{tabular} & 19.7 & 4.7 & 11.9 & 6.5 \\
\hline 3 & 13.5 & 12.3 & 12.7 & 5.8 & 11.0 & 5.5 \\
\hline 4 & 11.5 & 10.6 & 6.2 & 7.0 & 10.5 & 7.7 \\
\hline 5 & 9.2 & 9.1 & 4.7 & 8.5 & 9.5 & 11.3 \\
\hline 6 & 8.1 & 8.0 & 8.5 & 9.6 & 8.9 & 7.7 \\
\hline 7 & 7.1 & 7.0 & 4.3 & 10.5 & 8.3 & 7.6 \\
\hline 8 & 6.3 & 6.1 & 4.3 & 12.6 & 7.7 & 5.3 \\
\hline 9 & 4.5 & 5.5 & 12.3 & 14.7 & 7.6 & 11.4 \\
\hline 10 & 6.5 & 6.0 & 7.8 & 23.2 & 9.8 & 25.1 \\
\hline Mean & 4.4 years & 4.30 years & 4.5 years & 7.0 years & 5.0 years & 6.2 years \\
\hline \multirow[t]{3}{*}{$\mathbf{N}$} & & & 482 & & & 409 \\
\hline & \multicolumn{6}{|c|}{ Whites } \\
\hline & Hazard rate & $\begin{array}{c}\text { Variance } \\
\text { components }\end{array}$ & $\begin{array}{c}\text { Direct } \\
\text { tabulations }\end{array}$ & $\begin{array}{l}\text { Hazard } \\
\text { rate }\end{array}$ & $\begin{array}{c}\text { Variance } \\
\text { components }\end{array}$ & $\begin{array}{c}\text { Direct } \\
\text { tabulations }\end{array}$ \\
\hline 1 & 32.9 & 24.1 & 40.6 & 13.3 & 17.7 & 26.9 \\
\hline 2 & 21.4 & 16.2 & 13.6 & 11.6 & 13.7 & 18.4 \\
\hline 3 & 13.8 & 12.9 & 8.8 & 10.6 & 12.1 & 13.9 \\
\hline 4 & 9.8 & 10.7 & 12.2 & 10.4 & 10.5 & 5.1 \\
\hline 5 & 6.6 & 8.9 & 4.5 & 9.8 & 9.5 & 8.0 \\
\hline 6 & 4.4 & 7.3 & $\overline{8.2}$ & 8.5 & 8.4 & 7.3 \\
\hline 7 & 3.2 & 6.1 & 2.7 & 7.9 & 7.7 & 5.3 \\
\hline 8 & 2.5 & $\overline{5.3}$ & 3.1 & 7.8 & 6.8 & 5.0 \\
\hline 9 & 2.5 & 4.2 & 3.7 & 7.8 & $\overline{6.4}$ & 5.9 \\
\hline 10 & 2.9 & 4.5 & 2.6 & 12.3 & 7.1 & 4.1 \\
\hline Mean & 3.1 years & 4.0 years & 3.2 years & 5.2 years & 4.6 years & 3.8 years \\
\hline $\mathbf{N}$ & & & 277 & & & 91 \\
\hline
\end{tabular}

Distributions shown are simulated for individuals beginning a stay in poverty at age 30 , and where the household head has less than a high school education. 


\section{Appendix \\ Calculation of Standard Error Estimates Using Balanced Half-Sample Replications}

This section describes the estimation of standard errors in Tables 1 through 5 using balanced half-sample replications; see Kish and Frankel (1970) or Wolter (1985), Chapter 3, for more details. This method makes use of variables on the PSID that assign each household to one of 32 different strata, and to one of two primary sampling units within each stratum.

Given these assignments, a series of half-samples is created by selecting one of the two sampling units from within each strata. A large number of different half-samples is possible, given the various possible selections across all 32 strata. In order to minimize the variance of the variance estimator, the half-samples are selected in a particular way. Wolter (1985) provides a series of orthogonal matrices (known as Hadamard matrices) that describe which unit should be selected from each of the strata to guarantee that the variance estimator is as precise as possible.

Let $\hat{\beta}$ be a parameter estimate based on the entire sample. Then, from each of 32 different half-samples, let $\hat{\beta}_{\alpha}$ be the same parameter estimated from the $\alpha$-th half-sample. The variance estimator, which can be shown to be a consistent estimator under certain regularity conditions (Wolter, 1985, Appendix B), is then given by:

$$
v_{b h r}(\hat{\beta})=\sum_{\alpha=1}^{32}\left(\hat{\beta}_{\alpha}-\hat{\beta}\right) / 32
$$

In the case of a linear estimator, this formula, given the strategic selection of half-samples described above, will reproduce exactly the "textbook" variance estimator for a complex survey design. In the case of non-linear estimators the finite-sample correspondence is approximate. 
Wolter (1985) describes studies establishing the appropriateness of balanced half-sample variance estimators in a variety of specific non-linear applications. 
Table A1

Sample Sizes

\begin{tabular}{|r|r|r|r|r|}
\hline & \multicolumn{2}{|c|}{ Blacks } & \multicolumn{2}{c|}{ Whites } \\
\hline & $\begin{array}{l}\text { Exit } \\
\text { hazard }\end{array}$ & $\begin{array}{l}\text { Re- } \\
\text { entry } \\
\text { hazard }\end{array}$ & $\begin{array}{l}\text { Exit } \\
\text { hazard }\end{array}$ & $\begin{array}{l}\text { Re- } \\
\text { entry } \\
\text { hazard }\end{array}$ \\
\hline $\begin{array}{r}1969-1988 \\
\text { sample }\end{array}$ & & & & \\
\hline Persons & 6,854 & 6,400 & 4,000 & 3,794 \\
\hline Person-years & 36,783 & 44,826 & 13,723 & 31,760 \\
\hline & & & & \\
\hline $\begin{array}{r}1973-1988 \\
\text { sample }\end{array}$ & & & & \\
\hline Persons & 7,157 & 6,040 & 3,662 & 3,653 \\
\hline Person-years & 42,902 & 39,016 & 12,910 & 28,995 \\
\hline
\end{tabular}




\section{REFERENCES}

Abowd, John, and David Card (1989). "On the Covariance Structure of Earnings and Hours Changes." Econometrica 57:411-445.

Ashworth, Karl, Martha Hill, and Robert Walker (1994). "Patterns of Childhood Poverty: New Challenges for Policy." Journal of Policy Analysis and Management 13:658-680.

Baker, Michael (1995). "Growth Rate Heterogeneity and the Covariance Structure of Earnings." Mimeo.

Bane, Mary Jo, and David Ellwood (1986). "Slipping Into and Out of Poverty: The Dynamics of Spells." Journal of Human Resources 21: 1-23.

Coleman, Thomas (1989). "Unemployment Behavior: Evidence from the CPS Work Experience Survey." Journal of Human Resources 24:1-38.

Duncan, Greg (1983). "The Implications of Changing Family Composition for the Dynamic Analysis of Family Economic Well-Being." In Panel Data on Incomes. Ed. A.B. Atkinson. London: London School of Economics.

Duncan, Greg, et al. (1984). Years of Poverty. Years of Plenty. Ann Arbor: Survey Research Center.

Duncan, Greg, and Willard Rodgers (1991). "Has Children's Poverty Become More Persistent?" American Sociological Review 56: 538-549.

Eberwein, Curtis, John Ham, and Robert LaLonde (1994). "The Impact of Classroom Training on the Employment Histories of Disadvantaged Women: Evidence from Experimental Data." Mimeo.

Ellwood, David (1986). "Targeting 'Would Be' Long-Term Recipients of AFDC." Mathematica Policy Research report prepared for U.S. Department of Health and Human Services.

Gottschalk, Peter (1982). "Earnings Mobility: Permanent Change or Transitory Fluctuations?" Review of Economics and Statistics 64:450-56.

Gottschalk, Peter, Sara McLanahan, and Gary Sandefur (1994). "The Dynamics and Intergenerational Transmission of Poverty and Welfare Participation." In Confronting Poverty: Prescriptions for Change. Eds. Sheldon Danziger, Gary Sandefur, and Daniel Weinberg. Cambridge: Harvard University Press. 
Gottschalk, Peter, and Robert Moffitt (1994). "Welfare Dependence: Concepts, Measures, and Trends." American Economic Review 84: 38-42.

Ham, John, and Samuel Rea (1987). "Unemployment Insurance and Male Unemployment Duration in Canada." Joumal of Labor Economics 5: 325-353.

Hamilton, James (1989). "A New Approach to the Economic Analysis of Nonstationary Time Series and the Business Cycle." Econometrica 57: 357-384.

Hause, John (1977). "The Covariance Structure of Earnings." Annals of Economic and Social Measurement 6: 335-365.

Heckman, James (1981). "The Incidental Parameters Problem and the Problem of Initial Conditions in Estimating a Discrete Time-Discrete Data Stochastic Process." In Structural Analysis of Discrete Data with Econometric Applications. Eds. Charles Manski and Daniel McFadden. Cambridge: MIT Press.

Heckman, James, and Burton Singer (1984a). "A Method for Minimizing the Impact of Distributional Assumptions in Econometric Models for Duration Data." Econometrica 52: 271-320.

Heckman, James, and Burton Singer (1984b). "Social Science Duration Analysis." In Longitudinal Analysis of Labor Market Data. Eds. James Heckman and Burton Singer. Cambridge: Cambridge University Press.

Hill, Martha (1981). "Some Illustrative Design Effects: Proper Sampling Errors Versus Simple Random Sample Assumptions." In Eive Thousand American Families--Patterns of Economic Progress. Volume IX. Eds. Martha Hill, Daniel Hill, and James Morgan. Ann Arbor: Institute for Social Research.

Kish, Leslie, and Martin Frankel (1970). "Balanced Repeated Replication for Standard Errors." Journal of the American Statistical Association 67: 1071-1094.

Lillard, Lee, and Yoram Weiss (1979). "Components of Variation in Panel Earnings Data: American Scientists 1960-1970." Econometrica 47: 437-454.

Lillard, Lee, and Robert Willis (1978). "Dynamic Aspects of Earnings Mobility." Econometrica 46: 985-1012.

Moffitt, Robert, and Michael Rendall (1993). "Cohort Trends in the Lifetime Distribution of Female Headship in the U.S., 1968-1985." Brown University Population Studies and Training Center Working Paper 93-90.

Neftci, Salih N. (1984). "Are Economic Time Series Asymmetric over the Business Cycle?" Journal of Political Economy 92: 307-328. 
Sichel, Daniel (1993). "Business Cycle Asymmetry: A Deeper Look." Economic Inquiry 31: 224-236.

Stevens, Ann Huff (1994). "The Dynamics of Poverty Spells: Updating Bane and Ellwood." American Economic Review 84: 34-37.

Stevens, Ann Huff (1995). "Essays on Income Dynamics: Long-Term Effects of Job Displacement and Measuring the Persistence of Poverty Over Multiple Spells." Ph.D. Dissertation, University of Michigan.

Survey Research Center (1985). Panel Study of Income Dynamics: Procedures and Tape Codes 1983 Interviewing Year. Ann Arbor: Institute for Social Research.

Wolter, Kirk (1985). Introduction to Variance Estimation. New York: Springer-Verlag. 